\title{
The Effects of Build Parameters and Strain Rate on the Mechanical Properties of FDM 3D-Printed Acrylonitrile Butadiene Styrene
}

\author{
Kemar Hibbert ${ }^{1}$, Grant Warner ${ }^{1}$, Celeste Brown' ${ }^{1}$, Olusegun Ajide ${ }^{1,2}$, Gbadebo Owolabi ${ }^{1}$, \\ Amin Azimi ${ }^{*}$
}

${ }^{1}$ Department of Mechanical Engineering, Howard University, Washington DC, USA

${ }^{2}$ Department of Mechanical Engineering, University of Ibadan, Ibadan, Nigeria

Email: ^amin.azimi@bison.howard.edu, ^aminazimi.kntu@gmail.com

How to cite this paper: Hibbert, K., Warner, G., Brown, C., Ajide, O., Owolabi, G. and Azimi, A. (2019) The Effects of Build Parameters and Strain Rate on the Mechanical Properties of FDM 3D-Printed Acrylonitrile Butadiene Styrene. Open Journal of Organic Polymer Materials, 9, 1-27. https://doi.org/10.4236/ojopm.2019.91001

Received: December 17, 2018

Accepted: January 28, 2019

Published: January 31, 2019

Copyright $\odot 2019$ by author(s) and Scientific Research Publishing Inc. This work is licensed under the Creative Commons Attribution International License (CC BY 4.0).

http://creativecommons.org/licenses/by/4.0/

cc) (i) Open Access

\begin{abstract}
In this paper, the effects of build parameters on the mechanical properties of 3D-printed acrylonitrile butadiene styrene (ABS) produced using fused deposition modeling (FDM) are investigated. Full factorial experimental design incorporating a 2-level, 3-factor design with raster angle, layer thickness and interior fill style was carried out. Tensile tests were performed at four different strain rates to determine how the build parameters influence the mechanical properties of the 3-D printed ABS and to assess its strain rate sensitivity under quasi-static loading. It was found that the modulus of toughness of ABS material is most influenced by raster angle, while the interior fill style is the most dominant build parameter that dictates the specimen's modulus of resilience, yield strength and ultimate tensile strength. At all strain rates, it is further revealed that higher mean values of yield strength, ultimate tensile strength and modulus of resilience were obtained when the interior fill style is solid as opposed to high density. This can be attributed to the denser structure and higher effective cross-sectional area in solid interior fill style in comparison with high density interior fill style. However, the influence of the layer thickness on the investigated mechanical properties was found to be inconsistent. It was noted that specimens built with both $0.254 \mathrm{~mm}$ layer thickness and the cross $\left[0^{\circ} / 90^{\circ}\right]$ raster angle had superior mechanical properties when compared to those built with the $0.3302 \mathrm{~mm}$ layer thickness and cross $\left[0^{\circ} / 90^{\circ}\right]$ raster angle. This suggests that there is a key interaction between the layer thickness and the raster angle. At any FDM build parameter, it was found that all the mechanical properties investigated in this work exhibited modest sensitivity to strain rates. This study has provided a platform for an appropriate selection of build parameters combinations and strain rates for
\end{abstract}


additive manufacturing of $3 \mathrm{D}$-printed $\mathrm{ABS}$ with improved mechanical properties.

\section{Keywords}

Build Parameters, Mechanical Properties, Additive Manufacturing, 3D

Printing, Acrylonitrile Butadiene Styrene

\section{Introduction}

The ever-increasing demand for the development of new performance materials is attracting unprecedented renewed research interests in materials science. However, the rapid production of critical machine components and complex structures with high precision, at minimal cost, and with the required service properties may not be feasible by the conventional manufacturing techniques [1]-[8]. This was a strong motivation for the emergence of Additive Manufacturing (AM). Research concerns in AM have risen in a number of distinct ways [9]. It has gained prominence both in the popular media as well as the scientific journals [10] [11]. Research activities on the industrial applications of AM have led to an astronomical expansion in market for components produced through $A M$ [12]. In addition, there is the prediction of a global compound annual growth of $27 \%$ in AM [13] and the nearly $\$ 11$ billion industry in 2015 will increase to $\$ 26.7$ billion by 2019 . Furthermore, it was reported that the aggregate share of global AM by the United States, West European and Asian markets is expected to rise from $59.2 \%$ recorded in 2014 to an estimated $70 \%$ by 2019. According to [14], AM market has equally been projected to grow to $\$ 3.5$ billion in 2017 and to approximately $\$ 10$ billion in 2022. These exciting market reports may not be realized unless researchers redouble their efforts in the field of AM.

Additive manufacturing can be described as the process of adding material layer by layer to form a part [15]. This contrasts with the traditional method, often referred to as Subtractive Manufacturing (SM), in which material is removed from the bulk to form the desired component. It is a technique that surpasses SM as it opens up opportunity for handling complex shapes with great design flexibility, and reducing waste in the production of machine components [16] [17] [18] [19] [20]. This method has become very popular for industrial and domestic purposes as it provides opportunities for reducing lead time and maximizing inventory strategies [21]. Among different AM technologies available, FDM remains one of the most versatile techniques due to its inherent flexibility and rapid prototyping [4] [7] [12] [22]-[29]. In FDM process, a thermoplastic filament is heated and extruded using a robotically controlled head where the material is deployed layer by layer on a printing surface in a temperature-controlled environment [27] [30] [31] [32].

The existing and numerous potential applications of thermoplastic based materials such as ABS in manufacturing may be responsible for the renewed accep- 
tance of FDM for production of structural components (Bumper bars, clarinets, automotive interiors and valves, pipes and fittings, bathtubs, shower stalls, connectors, etc.) from polymers. Several research efforts have focused on FDM for manufacturing ABS based components. FDM process with laser-assisted heating was adopted by Jun et al. [33] for improving the forming quality and shape accuracy of ABS. Results showed that the laser-assisted heating in the forming of ABS thin-walled parts has enormous effect in increasing the temperature of the local forming regions than the pre and post laser-assisted heating. The significant benefit of this temperature rise at the local forming regions is the remarkable improvement in the tensile strength, shape accuracy and effective bonding width of thin-walled fabricated parts using laser-assisted heating. As part of efforts to improve the performance of 3D-printed ABS, graphene nanoplatelets were incorporated in ABS matrix by Dul et al. [27] using a completely solvent-free process and then extruded in filaments suitable for FDM. Although the incorporation of graphene nanoplatelets improved tensile modulus, substantial reductions in the ultimate tensile strength, strain at break, coefficient of thermal dilation and creep compliance of the ABS were observed.

The influence of build processing parameters of 3D using FDM on the quality of parts and their functionality has been documented in the literature [34]. Guessama et al. [35] investigated the anisotropic damage effect of 3D printed ABS from FDM. The authors adopted severe compression conditions to describe anisotropy induced when printing under different build orientations. The outcome of the study revealed inconsistent plastic damage. It was concluded in their work that printing orientation is a key build parameter to be considered in order to optimize service properties of FDM 3D printed ABS. While Griffiths et al. [36] studied the influence of FDM build parameters on processing efficiency and performance of build parts, Srivastava et al. [37] employed response surface methodology for optimizing FDM process parameters such as (contour width, raster width, air gap, raster angle, slice height and orientation). From the foregoing and other similar studies [38]-[44], it has been reported in literature that FDM build parameters have enormous effects on cost optimization and performance properties of ABS and other polymeric based materials. Despite that mechanical properties of polymers material are critical for their structural applications, available studies on the influence of FDM build parameters on the mechanical properties of 3D-printed polymer materials are limited.

In Griffiths et al. [36], experiments were designed and conducted to quantify the effects of FDM build parameters on the tensile strength and Young modulus of $3 \mathrm{D}$-printed parts. It was found that a maximum infill resulted to an improvement in the tensile strength. This is attributed to the fact that a maximum infill helps the production of solid build parts that are stronger than those produced using a honeycomb structure on the same material. A combination of infill level and a side slicing orientation were found to enhance the Young modulus of build parts. A $100 \%$ infill, $0.4 \mathrm{~mm}$ layer height and a slicing orientation were ef- 
fective for the optimization of the tensile strength and Young modulus. Wu et al. [41] investigated the effects of raster angle and layer thickness parameters on the mechanical properties of 3D-printed ABS and Polyether-ether-ketone (PEEK). It was found that raster angle and layer thickness have significant effects on their tensile, compressive and bending properties. The combination of $300 \mu \mathrm{m}$ layer thickness and $\left[0^{\circ} / 90^{\circ}\right]$ raster angle led to an optimal improvement in their mechanical properties. Although FDM build parameters demonstrated better mechanical properties for PEEK in comparison to ABS, the challenge of pore formation and poor interlayer bonding were reported by the authors as research gaps for future works. In Luzamin et al. [42], the influence of layer thickness, deposition angle and infill parameters on Flexural force in FDM built specimens was studied. It was shown that combinations of $10 \%$ infill and $60^{\circ}$ deposition angle reduced the total build time and improved the maximum flexural strength. The drawback of their works [42] is the issue of high minimum detectable effect size (MDES). Thus, for higher flexural strength at this combination of FDM build parameters, there is need for further research efforts towards reducing the MDES.

Kay [45] studied the effect of raster orientation on the structural response of 3D-printed ABS based material using FDM. The study showed that specimens with raster oriented in the direction of loading exhibited the highest strength. In a study performed by Roberson et al. [46], 3D-printed impact ABS test specimens were considered in order to compare the effect of stress concentrator fabrication on the impact test data from printing and machining approaches. This was done in four different build orientations. There was an evidence of sensitivity to build orientation in terms of impact resistance, impact energy and break energy. An attempt was made by Patel et al. [47] to examine the influence of crack length and layer orientation on 3D-printed ABS specimens. It was found that crack length and layer orientation dictate the fracture properties of the specimens. An increase in crack length enhances the stress intensity factor, but decreases the required fracture load. Riddick et al. [48] investigated the effects of build direction and orientation on the mechanical response and failure mechanism of the fabricated ABS specimens. The tensile strength, the elongation-at-break and the tensile modulus were characterized along with failure surfaces at different build direction and raster orientation $\left[-45^{\circ} /+45^{\circ}\right],\left[0^{\circ} / 90^{\circ}\right],\left[90^{\circ}\right]$. Their results showed that the tensile strength, elongation-at-break and tensile modulus were highly dependent upon raster angle and build direction.

The elasticity and yielding responses of $\mathrm{ABS}$ material created by $3 \mathrm{D}$ printing were investigated by Zou et al. [49]. The effect of printing orientation on the mechanical properties was quantitatively evaluated. It was found that printing orientation determines the precision or accuracy of results obtained. The correlation between the mechanical properties of part manufactured out from ABS using FDM and parameter such as layer thickness and orientation was investigated by Rankouhi et al. [50]. Statistical analysis of the data showed that thick- 
ness and raster orientation significantly influenced its mechanical properties. Mishra [51] reported that FDM build parameters such as raster fill pattern enormously influences the mechanical and wear resistance behaviors of 3Dprinted ABS specimen. Effort was made to minimize the anisotropic behavior by controlling the raster fill pattern during part buildings. It was found that an increase in part orientation and layer thickness increases the surface roughness and presence of residual stresses. Dawoud et al. [52] investigated the influence of selected FDM build parameters on the mechanical response of ABS. The authors explored variations in raster angle and gap as possible criteria for improving the mechanical behavior of ABS material. Maximum tensile and impact strengths were obtained in the study with raster angle of $\left[-45^{\circ} /+45^{\circ}\right]$ whereas $\left[0^{\circ} / 90^{\circ}\right] \mathrm{fa}-$ vored the attainment of the most enhanced flexural strength. It was however reported that a positive gap drastically reduced the investigated mechanical properties.

Owolabi et al. [32] carried out a study to understand the high strain rate dynamic behavior of 3D-printed ABS produced using FDM. Results obtained showed multiple stages of contraction and expansion during impact loading. The ring-like formation observed around layers of the specimen was noted to lead to the significant manifestation of multistage deformation behavior in 3D-printed ABS. This multistage collapse is an indication of potentials for novel energy absorption mechanism that can be explored at lower strain rates. The manner of fabrication using FDM which absorbed and released the energy thus acting as a multistage spring was attributed to the potential energy absorption mechanism. From the authors' findings, the choice of FDM as a production technique for 3D-printed ABS can be considered as beneficial if capability for energy absorption is highly paramount. An investigation on the thermo-mechanical creep properties of polymeric materials such as ABS using FDM was conducted by Turk et al. [53]. The outcome of this work showed that FDM build orientations significantly influences the mechanical properties of ABS. Huang et al. [30] investigated the effects of FDM build fiber orientation, filament dimensions, and chemical composition on the mechanical properties of ABS-printed components. Results of 3D-printed material manifested anisotropic properties at different filament extrusion directions. In the study carried out by Aliheidari et al. [54] on the fracture resistance measurement of FDM 3D-printed ABS, it was inferred that the degree of interlayer bonding influences the fracture resistance properties of ABS materials.

Despite the immeasurable prospects of AM such as FDM, its absolute exploitation in industries is still hindered due to unreliability in the mechanical response behaviors of ABS based components [55]. Parts processed through FDM typically have lower mechanical properties when compared to those processed via conventional manufacturing techniques. From the foregoing, inappropriate choice of FDM build parameters has been shown to be a strong limitation to maximizing the mechanical properties potentials of ABS based components. 
Apart from the fact that studies on the effects of various combinations of FDM build parameters on mechanical properties of 3D-printed ABS are very sparse, investigations on multiple build styles of three parameters combinations for each build style have not been sighted. In view of these research gaps, there is need for continuous rigorous research efforts in order to further elucidate the influences of different build parameters on the mechanical behaviors of ABS. In this work, an investigation is made into the effects of raster angle, layer thickness and interior fill style at different strain rates on the modulus of toughness and modulus of resilience of 3D-printed ABS which have been rarely reported in literature. In addition, the effects of these parameters on the yield strength and the ultimate tensile strength were studied to complement what have been earlier reported. The printer available for this study only had discrete layer thicknesses available making continued exploration of this parameter impossible. The attempt made on investigating the effects of eight distinct build styles (with three FDM build parameters combinations for each build style) and exploration of different strain rates can be considered as the novelty of the present work. The outcome of this study may provide more useful information for predicting mechanical properties of FDM build 3D-printed ABS.

\section{Materials and Methods}

The Specimens used in this work were manufactured from commercially available ABS P430 filament. This filament was designed for use with the procured 3D printer, the Stratasys Dimension 1200es. The machine's build envelop was 254 $\mathrm{mm} \times 254 \mathrm{~mm} \times 305 \mathrm{~mm}$. Full factorial design experiment was performed. This experiment incorporated a 2-level, 3 -factor design with raster angle, layer thickness and interior fill style as illustrated in Table 1. Response variables under investigation include the yield strength, ultimate tensile strength (UTS), modulus of resilience and modulus of toughness. There was a total of 8 build combinations as indicated in Table 2.

The ASTM dog bone test specimen was designed using Siemens NX 10 CAD software. The test specimens were designed to conform to ASTM D-638, Standard Test Method for Tensile Testing of Plastics, as illustrated in Figure 1. The CAD file was then exported as an STL file such that it could be interpreted by the FDM software, CatalystEX. Prior to testing, specimens were visually inspected for any physical damage and labelled per their build style and production date. Specimens were then conditioned for a minimum of 48 hours at 77 degrees Fahrenheit to comply with the ASTM D638 standard. Upon completing the conditioning period, uniaxial tensile tests were carried out using the $50 \mathrm{kN}$ Instron 5569A tensile testing machine equipped with Bluehill data acquisition software, as shown in Figure 2. Testing was carried out at four different strain rates: $0.127 \mathrm{~cm} / \mathrm{min}, 0.5 \mathrm{~cm} / \mathrm{min}, 5 \mathrm{~cm} / \mathrm{min}$ and $10 \mathrm{~cm} / \mathrm{min}$.

For each build combination in Table 2, five specimens were produced, 40 per strain rate and 160 specimens in total. The data was recorded and analyzed using 
Table 1. FDM process parameters and associated levels.

\begin{tabular}{ccccc}
\hline Factor & Label & Unit & Low Level (-) & High Level (+) \\
\hline Raster Angle & $\mathrm{A}$ & Degrees & $45^{\circ} /-45^{\circ}$ & $0^{\circ} / 90^{\circ}$ \\
Layer thickness & $\mathrm{B}$ & $\mathrm{mm}$ & 0.254 & 0.3302 \\
Interior Fill Style & $\mathrm{C}$ & $\mathrm{N} / \mathrm{A}$ & Solid & High Density \\
\hline
\end{tabular}

Table 2. Full factorial experimental design.

\begin{tabular}{cccc}
\hline Build & Factor 1 : Raster Angle & Factor $2:$ Layer Thickness Factor 3: Interior Fill Style \\
\hline 1 & $0^{\circ} / 90^{\circ}(+)$ & $0.254(-)$ & High Density $(+)$ \\
2 & $0^{\circ} / 90^{\circ}(+)$ & $0.3302(+)$ & High Density $(+)$ \\
3 & $45^{\circ} /-45^{\circ}(-)$ & $0.3302(+)$ & High Density $(+)$ \\
4 & $0^{\circ} / 90^{\circ}(+)$ & $0.3302(+)$ & Solid $(-)$ \\
5 & $45^{\circ} /-45^{\circ}(-)$ & $0.3302(+)$ & Solid $(-)$ \\
6 & $45^{\circ} /-45^{\circ}(-)$ & $0.254(-)$ & Solid $(-)$ \\
7 & $45^{\circ} /-45^{\circ}(-)$ & $0.254(-)$ & High Density $(+)$ \\
8 & $0^{\circ} / 90^{\circ}(+)$ & $0.254(-)$ & Solid $(-)$ \\
\hline
\end{tabular}

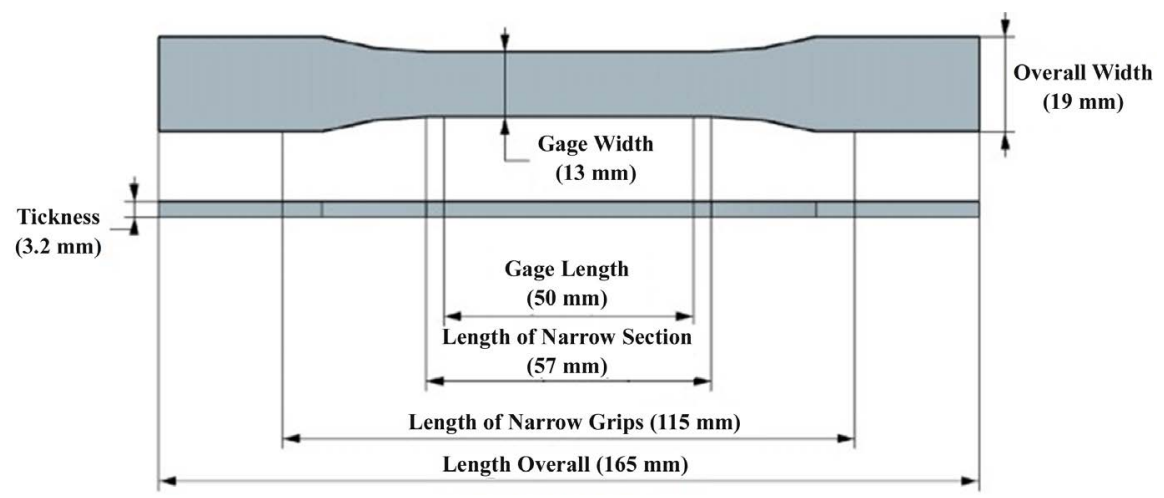

Figure 1. ASTM D638 Dog-Bone Test Specimen [56].

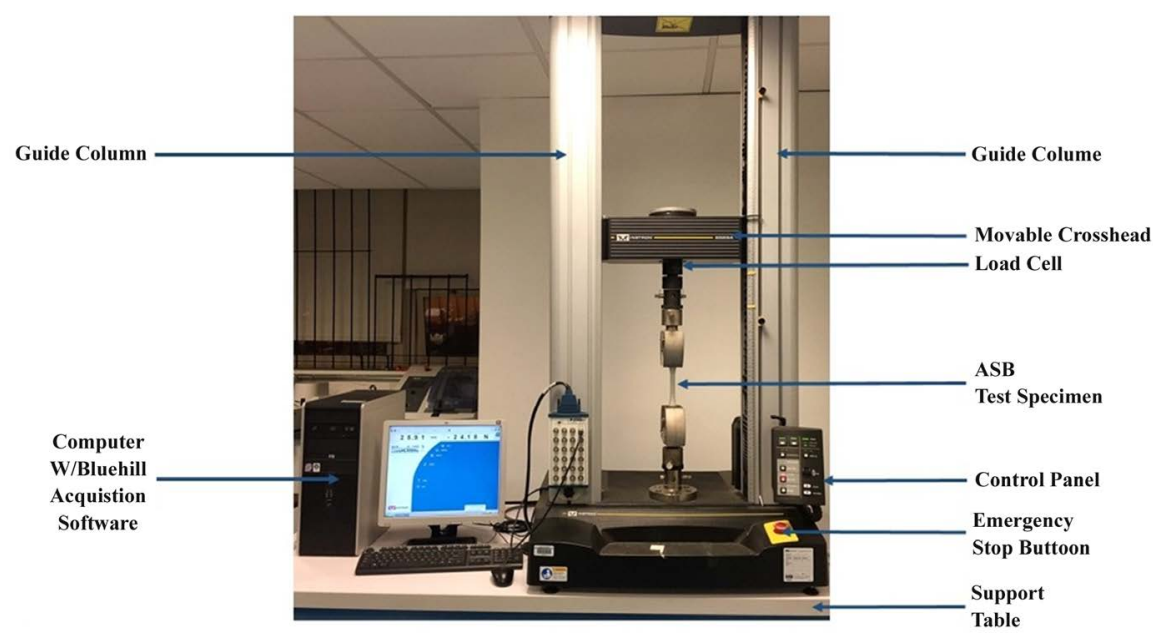

Figure 2. Instron Universal Tester Experimental Setup. 
the Bluehill data acquisition software. The yield strength was calculated using the $0.2 \%$ offset method, while the modulus of resilience and the modulus of toughness were calculated by finding the area under the stress-strain curve up to the yield point and the point of fracture, respectively. Statistical significance was determined using IBM's SPSS statistics software. A factorial Analysis of Variance (ANOVA) with four independent variables (raster angle, layer thickness, interior fill style, and strain rate) was conducted at a $95 \%$ confidence interval (the significant or risk level $\alpha$ was set at 0.05).

\section{Results and Discussion}

\subsection{Comparison of the Effect of Build Parameter on the Mechanical Properties of ABS}

In Griffiths et al. [36], the ultimate tensile strength that was obtained with $100 \%$ infill build parameter is similar to that of the present work where the highest ultimate tensile strength was obtained with solid interior fill style. The layer thickness values in the present work and that of [36] differs by $36.5 \%$, in a build style consisting of interior fill and layer thickness parameters combination. Among the $\left[45^{\circ} /-45^{\circ}\right],\left[0^{\circ}\right],\left[90^{\circ}\right]$ and $\left[0^{\circ} / 90^{\circ}\right]$ raster angles investigated by Riddick et al. [48], the raster angle $\left[45^{\circ} /-45^{\circ}\right]$ in the vertical build specimens of ABS exhibited the highest ultimate tensile strength of $19.80 \mathrm{MPa}$. Whereas the present study achieved optimum ultimate tensile strength with raster angle of $\left[0^{\circ} / 90^{\circ}\right]$. The optimal ultimate tensile strength of $27.30 \mathrm{MPa}$ was achieved in this work with build style 8 (from optimum combination of build parameters: $\left[0^{\circ} / 90^{\circ}\right]$ raster angle, $0.254 \mathrm{~mm}$ layer thickness and solid interior fill style). In Rankouhi et al. [50] and the present study, the choice of low layer thickness seemed to favor the attainment of the highest ultimate tensile strength. Their tensile test results showed that ABS samples printed with $0.200 \mathrm{~mm}$ layer thickness exhibited higher ultimate tensile strength compared with $0.400 \mathrm{~mm}$ layer thickness. This is very much similar to the results of the present study where $0.254 \mathrm{~mm}$ layer thickness displayed higher ultimate tensile strength than the layer thickness of $0.3302 \mathrm{~mm}$. The maximum ultimate tensile strength was obtained in the study of Dawoud et al. [52] with raster angle of $\left[-45^{\circ} /+45^{\circ}\right]$ contrary to $\left[0^{\circ} / 90^{\circ}\right]$ obtained in the present work.

Based on the comparisons made to prior research efforts [36] [48] [50] [52], the results presented in this study on modulus of toughness and modulus of resilience of 3D-printed ABS using different build styles (combinations of raster angle, layer thickness and interior fill style for each style) and the effect of strain rate on their mechanical properties can be considered as novel contributions to the existing literature.

\subsubsection{Raster Angle Observations}

The raster angle had a primary influence on the modulus of toughness. This is seen most markedly when viewing Figure 3. There is a prominent difference between the modulus of toughness of all specimens built with the $\left[45^{\circ} /-45^{\circ}\right]$ 


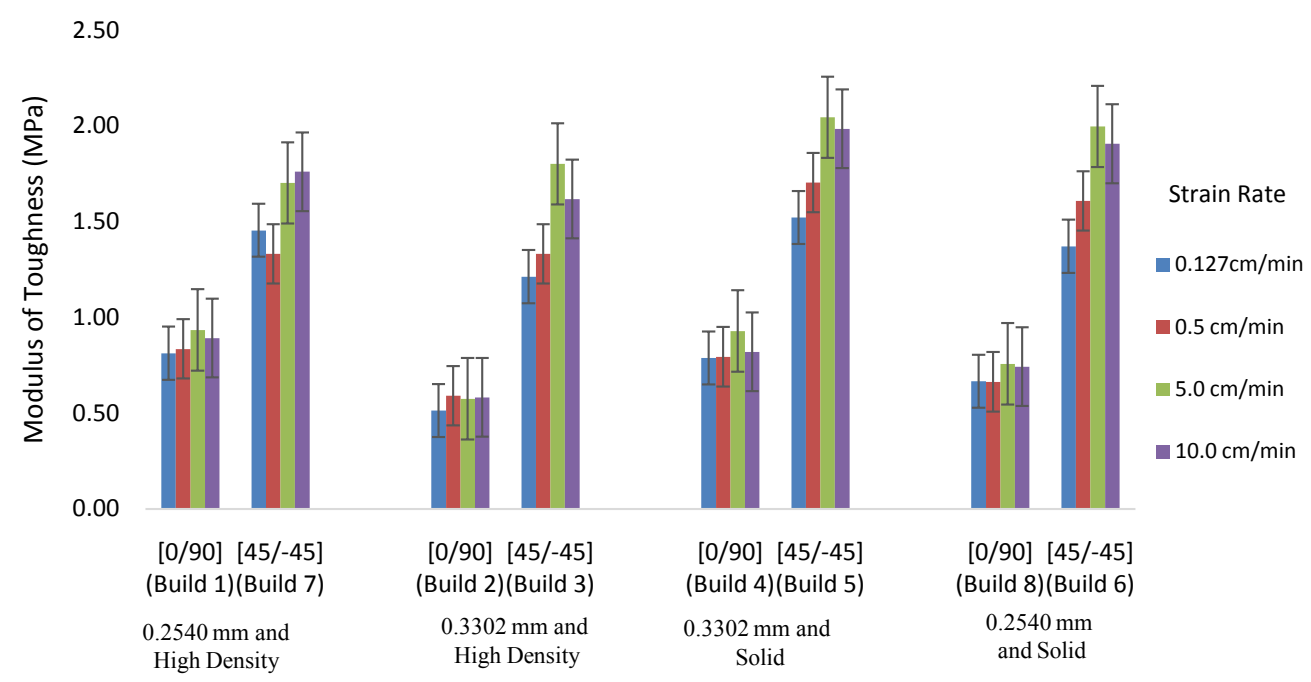

Figure 3. Effect of Raster Angle on Modulus of Toughness.

raster angle when compared to specimens built with the $\left[0^{\circ} / 90^{\circ}\right]$ raster angle. This observation was consistent throughout the experiment when comparing specimens built with the crisscross $\left[45^{\circ} /-45^{\circ}\right]$ raster angle versus specimens built with the cross $\left[0^{\circ} / 90^{\circ}\right]$ raster angle. This difference in raster angle can lead to an increase of up to $200 \%$ in modulus of toughness in favor of specimens built with the $\left[45^{\circ} /-45^{\circ}\right]$ raster angle. The results for the other material responses were not as clear. For example, Table 3 shows that build style 1, which was fabricated with the cross $\left[0^{\circ} / 90^{\circ}\right]$ raster angle, had a higher mean yield strength and modulus of resilience than build style 7 , which was fabricated using the crisscross $\left[45^{\circ} /-45^{\circ}\right]$ raster angle while holding the other parameters constant. However, build style 7 had a higher mean UTS and modulus of toughness when compared to build style 1 . As the strain rate is increased in Tables 4-6, some overlaps were observed for the mean values of yield strength, UTS, and even modulus of resilience for build style 1 and build style 7 . The constant overlaps of error bar and trend reversals in Figures 4-6 make it difficult to identify the relationship between the raster angle and the investigated mechanical properties.

\subsubsection{Layer Thickness}

Results obtained showed that the smaller layer thickness of $0.254 \mathrm{~mm}$ had superior mechanical properties, only for specimens built with the cross $\left[0^{\circ} / 90^{\circ}\right]$ raster angle (Factor 1: +). Specimens built with both $0.254 \mathrm{~mm}$ layer thickness and the cross $\left[0^{\circ} / 90^{\circ}\right]$ raster angle had superior mechanical properties when compared to those built with the $0.3302 \mathrm{~mm}$ layer thickness and cross $\left[0^{\circ} / 90^{\circ}\right]$ raster angle. When the $0.254 \mathrm{~mm}$ layer thickness is combined with the crisscross $\left[45^{\circ} /-45^{\circ}\right]$ raster angle, this trend is either reversed or not distinct. This suggests that there may be key interaction between the layer thickness and the raster angle that dictated the mechanical properties of the specimens. This observation is illustrated in Figures 7-10. 
Table 3. Results for tests conducted at strain rate of $0.127 \mathrm{~cm} / \mathrm{min}$.

\begin{tabular}{cccccccc}
\hline $\begin{array}{c}\text { Build } \\
\text { Style }\end{array}$ & $\begin{array}{c}\text { Factor 1: } \\
\text { Raster Angle }\end{array}$ & $\begin{array}{c}\text { Factor 2: } \\
\text { Layer } \\
\text { Thickness }\end{array}$ & $\begin{array}{c}\text { Factor 3: Inte- } \\
\text { rior Fill Type }\end{array}$ & $\begin{array}{c}\text { Result } 1^{*} \text { Yield } \\
\text { Strength } \\
(\mathrm{MPa})\end{array}$ & $\begin{array}{c}\text { Result } 2^{*}: \\
\text { UTS } \\
(\mathrm{MPa})\end{array}$ & $\begin{array}{c}\text { Result } 3^{*} \text { : } \\
\text { Modulus of } \\
\text { Resilence } \\
(\mathrm{MPa})\end{array}$ & $\begin{array}{c}\text { Result } 4^{*} \text { Modulus of } \\
\text { Toughness } \\
(\mathrm{MPa})\end{array}$ \\
\hline 1 & $0^{\circ} / 90^{\circ}$ & 0.254 & High Density & 14.41 & 17.17 & 0.200 & 0.813 \\
2 & $0^{\circ} / 90^{\circ}$ & 0.3302 & High Density & 12.89 & 15.31 & 0.151 & 0.514 \\
3 & $45^{\circ} /-45^{\circ}$ & 0.3302 & High Density & 11.51 & 16.62 & 0.128 & 1.213 \\
4 & $0^{\circ} / 90^{\circ}$ & 0.3302 & Solid & 14.55 & 18.06 & 0.157 & 0.788 \\
5 & $45^{\circ} /-45^{\circ}$ & 0.3302 & Solid & 15.10 & 20.62 & 0.176 & 1.521 \\
6 & $45^{\circ} /-45^{\circ}$ & 0.254 & Solid & 15.58 & 20.89 & 0.179 & 1.371 \\
7 & $45^{\circ} /-45^{\circ}$ & 0.254 & High Density & 13.72 & 18.00 & 0.171 & 1.454 \\
8 & $0^{\circ} / 90^{\circ}$ & 0.254 & Solid & 17.56 & 20.82 & 0.214 & 0.666 \\
\hline
\end{tabular}

Table 4. Results for tests conducted at strain rate of $0.5 \mathrm{~cm} / \mathrm{min}$.

\begin{tabular}{cccccccc}
\hline $\begin{array}{c}\text { Build } \\
\text { Style }\end{array}$ & $\begin{array}{c}\text { Factor 1: } \\
\text { Raster Angle }\end{array}$ & $\begin{array}{c}\text { Factor 2: } \\
\text { Layer } \\
\text { Thickness }\end{array}$ & $\begin{array}{c}\text { Factor 3: } \\
\text { Interior Fill } \\
\text { Type }\end{array}$ & $\begin{array}{c}\text { Result } 1^{*}: \\
\text { Yield Strength } \\
(\mathrm{MPa})\end{array}$ & $\begin{array}{c}\text { Result } 2^{*}: \\
\text { UTS } \\
(\mathrm{MPa})\end{array}$ & $\begin{array}{c}\text { Result } 3^{*}: \\
\text { Modulus of } \\
\text { Resilence } \\
(\mathrm{MPa})\end{array}$ & $\begin{array}{c}\text { Result } 4^{*} \text { : } \\
\text { Toughness } \\
(\mathrm{MPa})\end{array}$ \\
\hline 1 & $0^{\circ} / 90^{\circ}$ & 0.254 & High Density & 17.65 & 19.37 & 0.240 & 0.835 \\
2 & $0^{\circ} / 90^{\circ}$ & 0.3302 & High Density & 15.79 & 17.24 & 0.211 & 0.591 \\
3 & $45^{\circ} /-45^{\circ}$ & 0.3302 & High Density & 14.13 & 18.48 & 0.178 & 1.332 \\
4 & $0^{\circ} / 90^{\circ}$ & 0.3302 & Solid & 18.75 & 19.79 & 0.253 & 0.794 \\
5 & $45^{\circ} /-45^{\circ}$ & 0.3302 & Solid & 21.65 & 23.99 & 0.332 & 1.704 \\
6 & $45^{\circ} /-45^{\circ}$ & 0.254 & Solid & 19.51 & 22.96 & 0.257 & 1.608 \\
7 & $45^{\circ} /-45^{\circ}$ & 0.254 & High Density & 16.41 & 19.03 & 0.244 & 1.332 \\
8 & $0^{\circ} / 90^{\circ}$ & 0.254 & Solid & 21.51 & 22.89 & 0.310 & 0.663 \\
\hline
\end{tabular}

Table 5. Results for tests conducted at strain rate of $5 \mathrm{~cm} / \mathrm{min}$.

\begin{tabular}{cccccccc}
\hline $\begin{array}{c}\text { Build } \\
\text { Style }\end{array}$ & $\begin{array}{c}\text { Factor 1: } \\
\text { Raster Angle }\end{array}$ & $\begin{array}{c}\text { Factor 2: } \\
\text { Layer } \\
\text { Thickness }\end{array}$ & $\begin{array}{c}\text { Factor 3: } \\
\text { Interior Fill } \\
\text { Type }\end{array}$ & $\begin{array}{c}\text { Result } 1^{*}: \\
\text { Yield } \\
\text { Strength } \\
(\mathrm{MPa})\end{array}$ & $\begin{array}{c}\text { Result } 2^{*}: \\
\text { UTS (MPa) }\end{array}$ & $\begin{array}{c}\text { Result } 3^{*}: \\
\text { Modulus of } \\
\text { Resilence } \\
(\mathrm{MPa})\end{array}$ & $\begin{array}{c}\text { Result } 4^{*} \text { Modulus of } \\
\text { Toughness } \\
(\mathrm{MPa})\end{array}$ \\
\hline 1 & $0^{\circ} / 90^{\circ}$ & 0.254 & High Density & 21.49 & 22.75 & 0.358 & 0.934 \\
2 & $0^{\circ} / 90^{\circ}$ & 0.3302 & High Density & 18.06 & 19.37 & 0.281 & 0.574 \\
3 & $45^{\circ} /-45^{\circ}$ & 0.3302 & High Density & 18.96 & 21.99 & 0.321 & 1.801 \\
4 & $0^{\circ} / 90^{\circ}$ & 0.3302 & Solid & 20.89 & 22.61 & 0.334 & 0.929 \\
5 & $45^{\circ} /-45^{\circ}$ & 0.3302 & Solid & 21.65 & 25.86 & 0.337 & 2.044 \\
6 & $45^{\circ} /-45^{\circ}$ & 0.254 & Solid & 21.86 & 26.06 & 0.329 & 1.997 \\
7 & $45^{\circ} /-45^{\circ}$ & 0.254 & High Density & 18.41 & 21.64 & 0.297 & 1.702 \\
8 & $0^{\circ} / 90^{\circ}$ & 0.254 & Solid & 24.68 & 26.24 & 0.407 & 0.757 \\
\hline
\end{tabular}


Table 6. Results for tests conducted at strain rate of $10 \mathrm{~cm} / \mathrm{min}$.

\begin{tabular}{cccccccc}
\hline $\begin{array}{c}\text { Build } \\
\text { Style }\end{array}$ & $\begin{array}{c}\text { Factor 1: } \\
\text { Raster Angle }\end{array}$ & $\begin{array}{c}\text { Factor 2: } \\
\text { Layer } \\
\text { Thickness }\end{array}$ & $\begin{array}{c}\text { Factor 3: } \\
\text { Interior Fill } \\
\text { Type }\end{array}$ & $\begin{array}{c}\text { Result } 1^{*} \text { Yield } \\
\text { Strength } \\
(\mathrm{MPa})\end{array}$ & $\begin{array}{c}\text { Result } 2^{*} \text { : } \\
\text { UTS (MPa) }\end{array}$ & $\begin{array}{c}\text { Result } 3^{*} \text { Modulus of } \\
\text { Resilence } \\
(\mathrm{MPa})\end{array}$ & $\begin{array}{c}\text { Result } 4^{*} \text { Modulus of } \\
\text { Toughness } \\
(\mathrm{MPa})\end{array}$ \\
\hline 1 & $0^{\circ} / 90^{\circ}$ & 0.254 & High Density & 21.99 & 23.72 & 0.372 & 0.892 \\
2 & $0^{\circ} / 90^{\circ}$ & 0.3302 & High Density & 17.58 & 19.86 & 0.269 & 0.582 \\
3 & $45^{\circ} /-45^{\circ}$ & 0.3302 & High Density & 18.82 & 22.41 & 0.322 & 1.618 \\
4 & $0^{\circ} / 90^{\circ}$ & 0.3302 & Solid & 20.75 & 24.06 & 0.306 & 0.8196 \\
5 & $45^{\circ} /-45^{\circ}$ & 0.3302 & Solid & 23.79 & 27.44 & 0.414 & 1.984 \\
6 & $45^{\circ} /-45^{\circ}$ & 0.254 & Solid & 23.51 & 27.03 & 0.403 & 1.907 \\
7 & $45^{\circ} /-45^{\circ}$ & 0.254 & High Density & 19.03 & 22.68 & 0.345 & 1.761 \\
8 & $0^{\circ} / 90^{\circ}$ & 0.254 & Solid & 23.51 & 27.30 & 0.355 & 0.743 \\
\hline
\end{tabular}

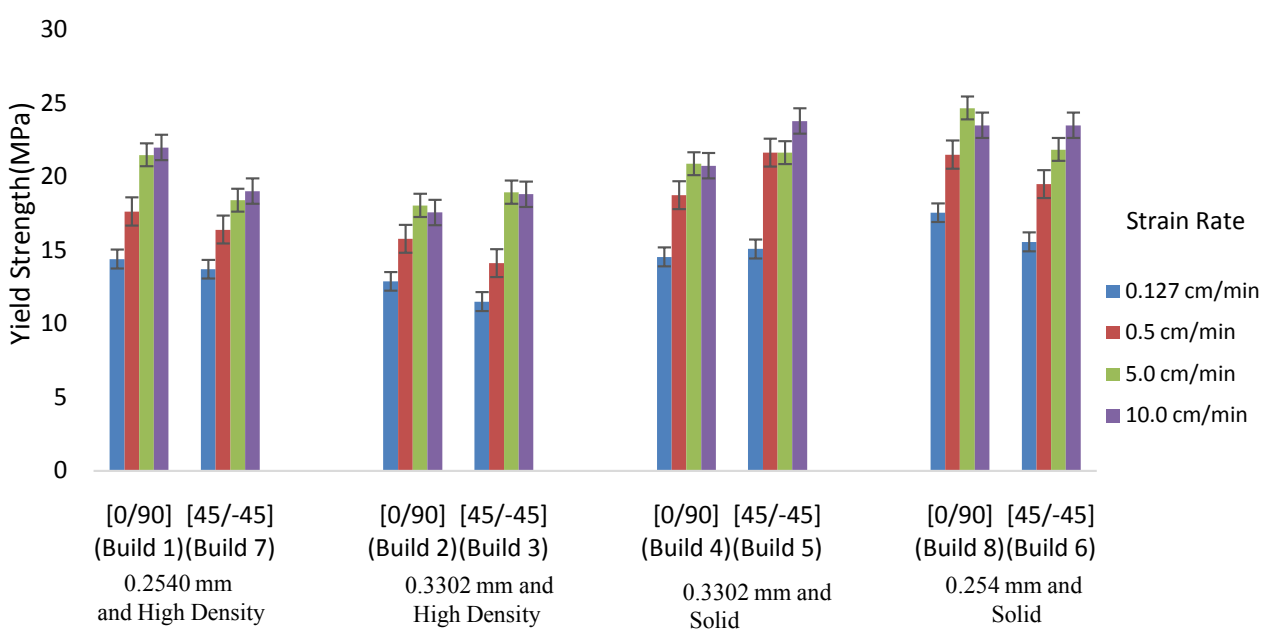

Figure 4. Effect of Raster Angle on Yield Strength.

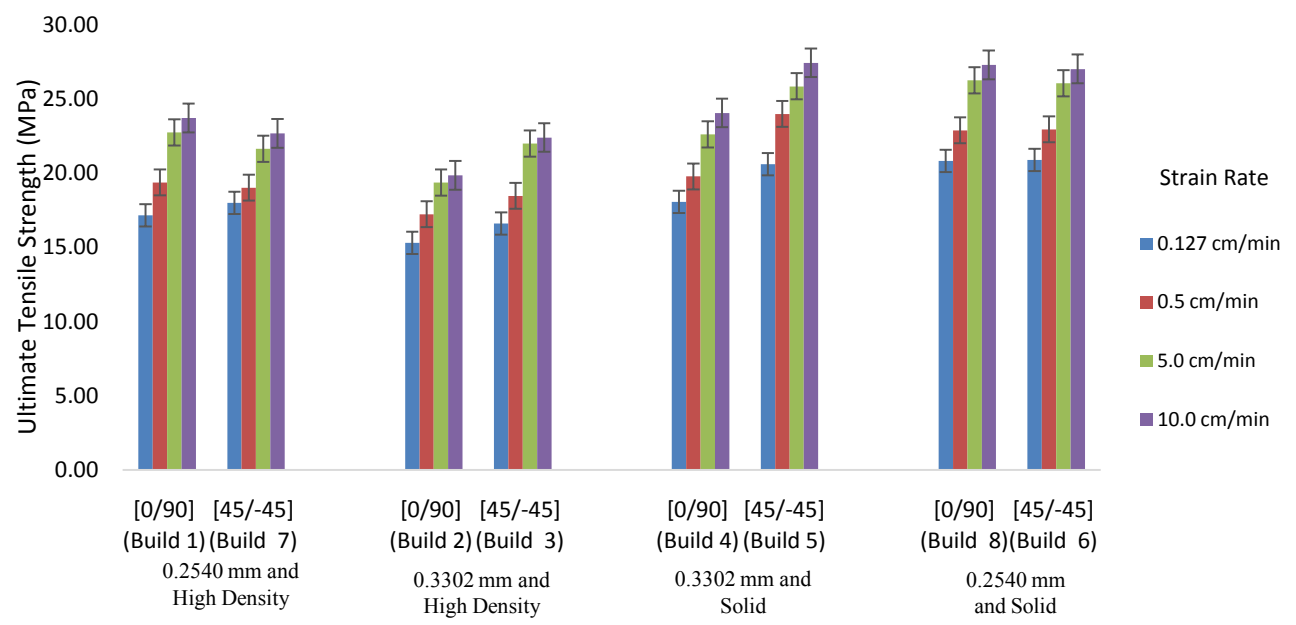

Figure 5. Effect of Raster Angle on Ultimate Tensile Strength.

\subsubsection{Interior Fill Style}

The effect of the interior fill style on the yield strength is illustrated in Figure 11. 


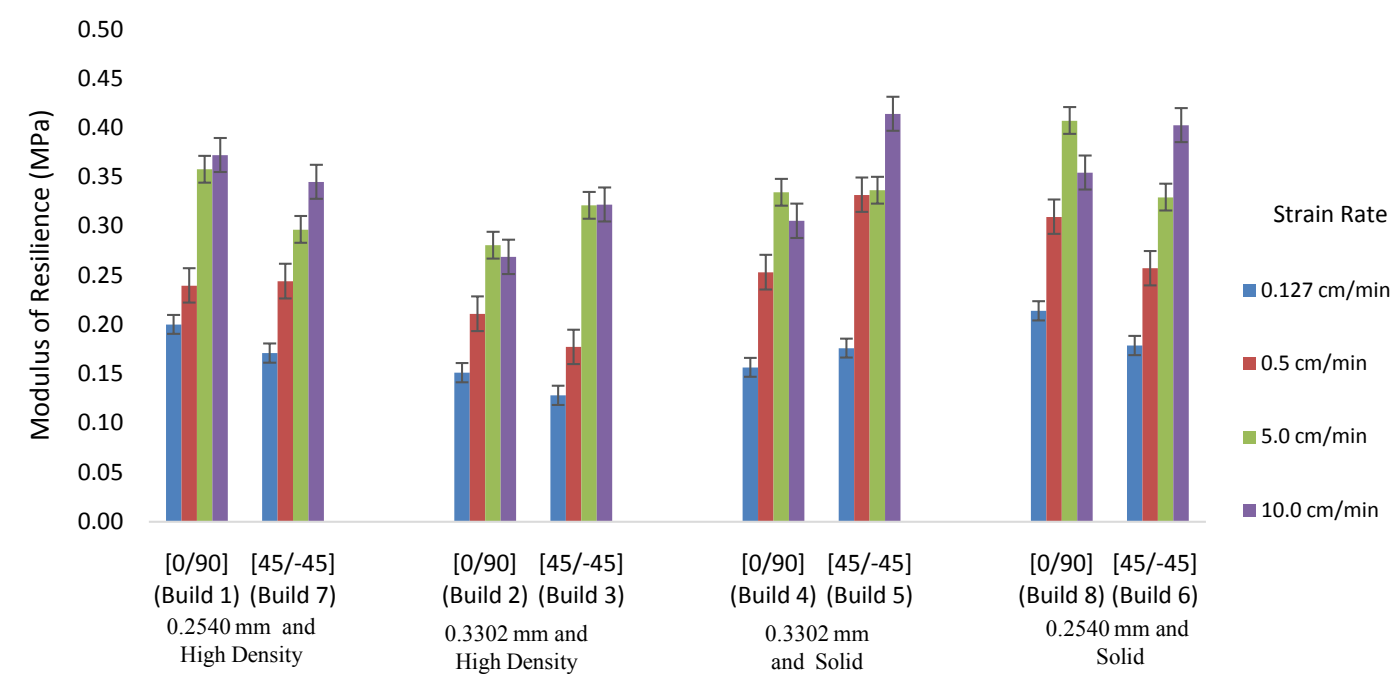

Figure 6. Effect of Raster Angle on Modulus of Resilience.

$$
30
$$

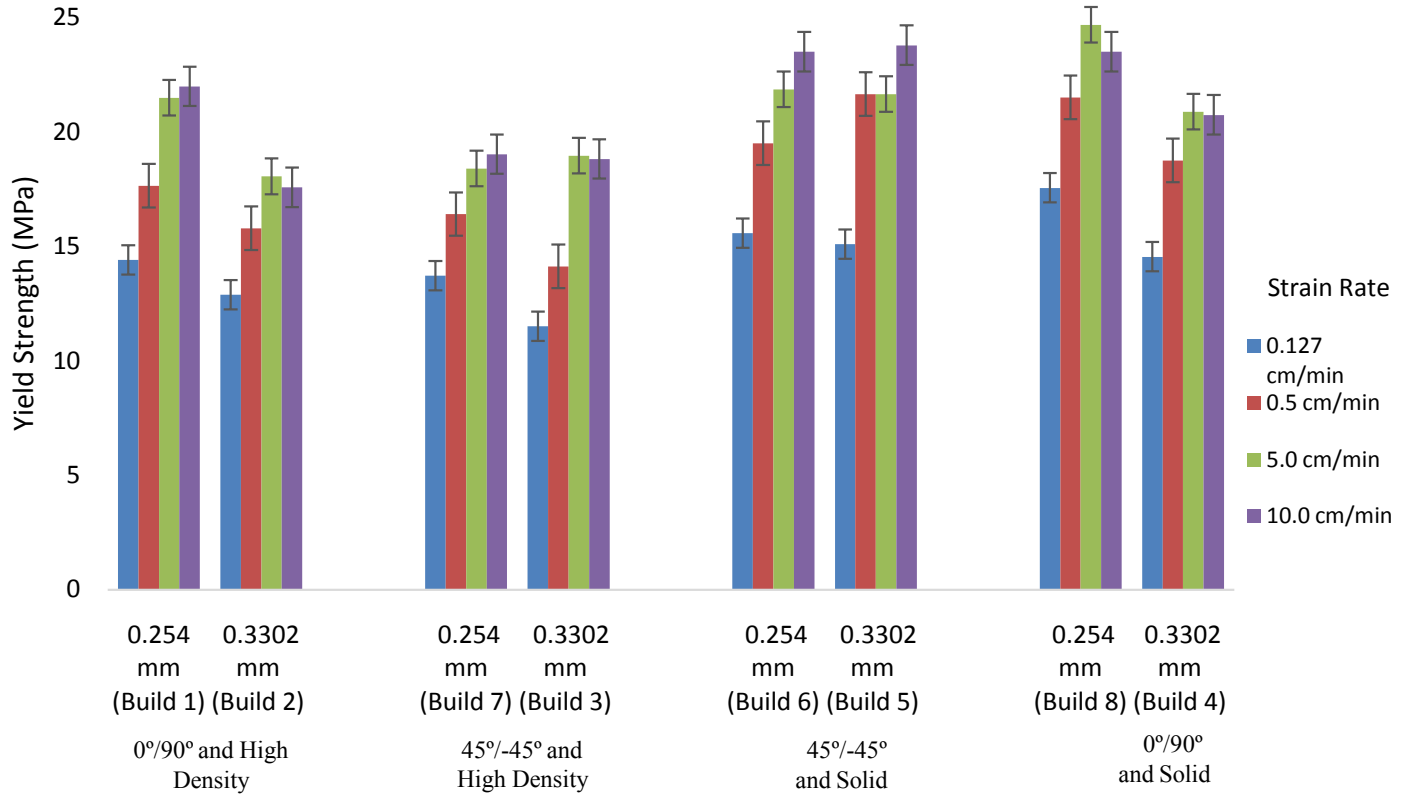

Figure 7. Effect of Layer Thickness on Yield Strength.

It is shown that build 8 (Solid) had higher average yield strength at all strain rates when compared to build 1 (High Density). This observed increase from $7 \%$ to about $53 \%$ is consistent across build comparisons in Figure 11 and at all strain rates. The effect of the interior fill style on the UTS is described using Figure 12. It was revealed that build 8 , with the solid interior fill style, had a higher UTS for all strain rates in comparison to build 1. This observation is consistent across all build comparisons in Figure 8 and at all strain rates with an increase ranging from $15 \%$ to $29 \%$. Similar observations were noticed on the effect of the interior fill style on the modulus of resilience and modulus of toughness as 
35.00

30.00

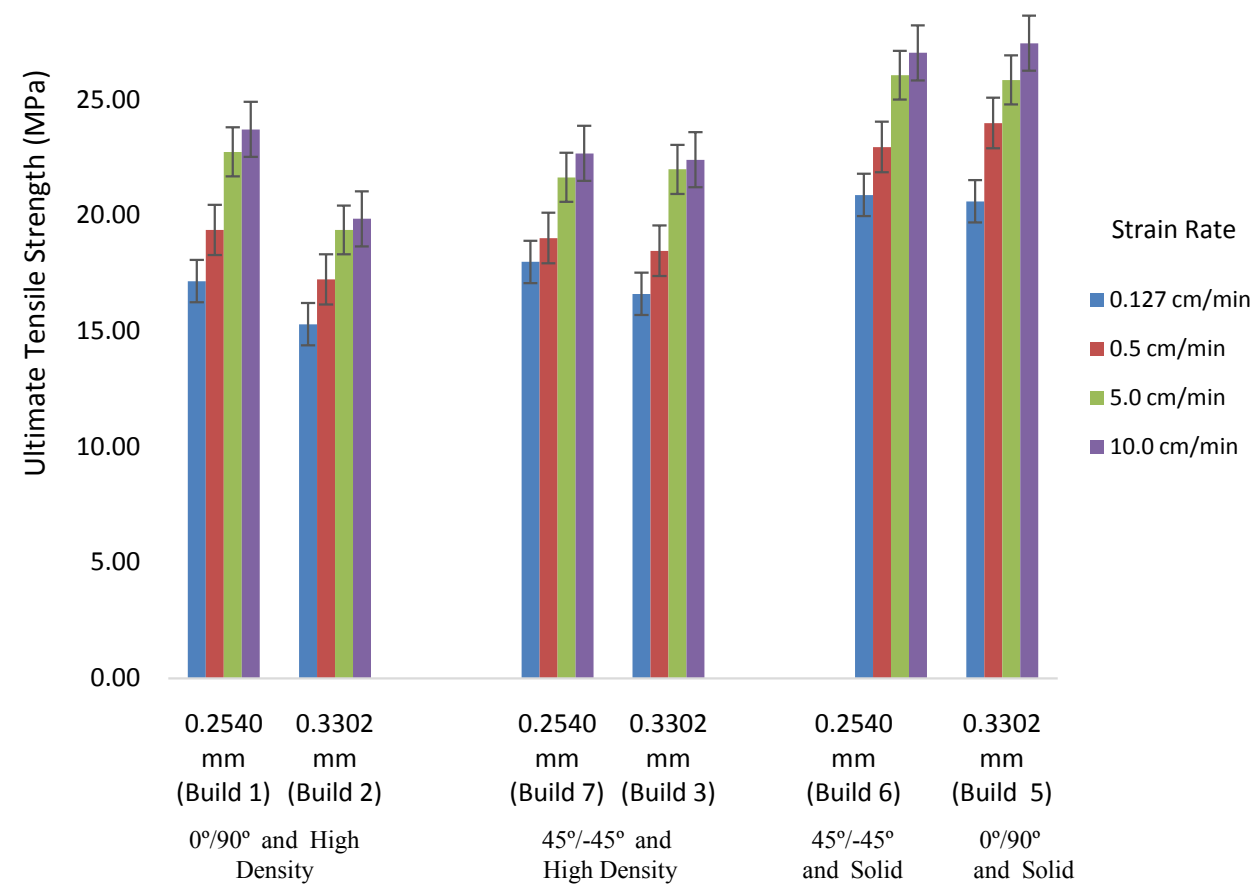

Figure 8. Effect of Layer Thickness on Ultimate Tensile Strength.

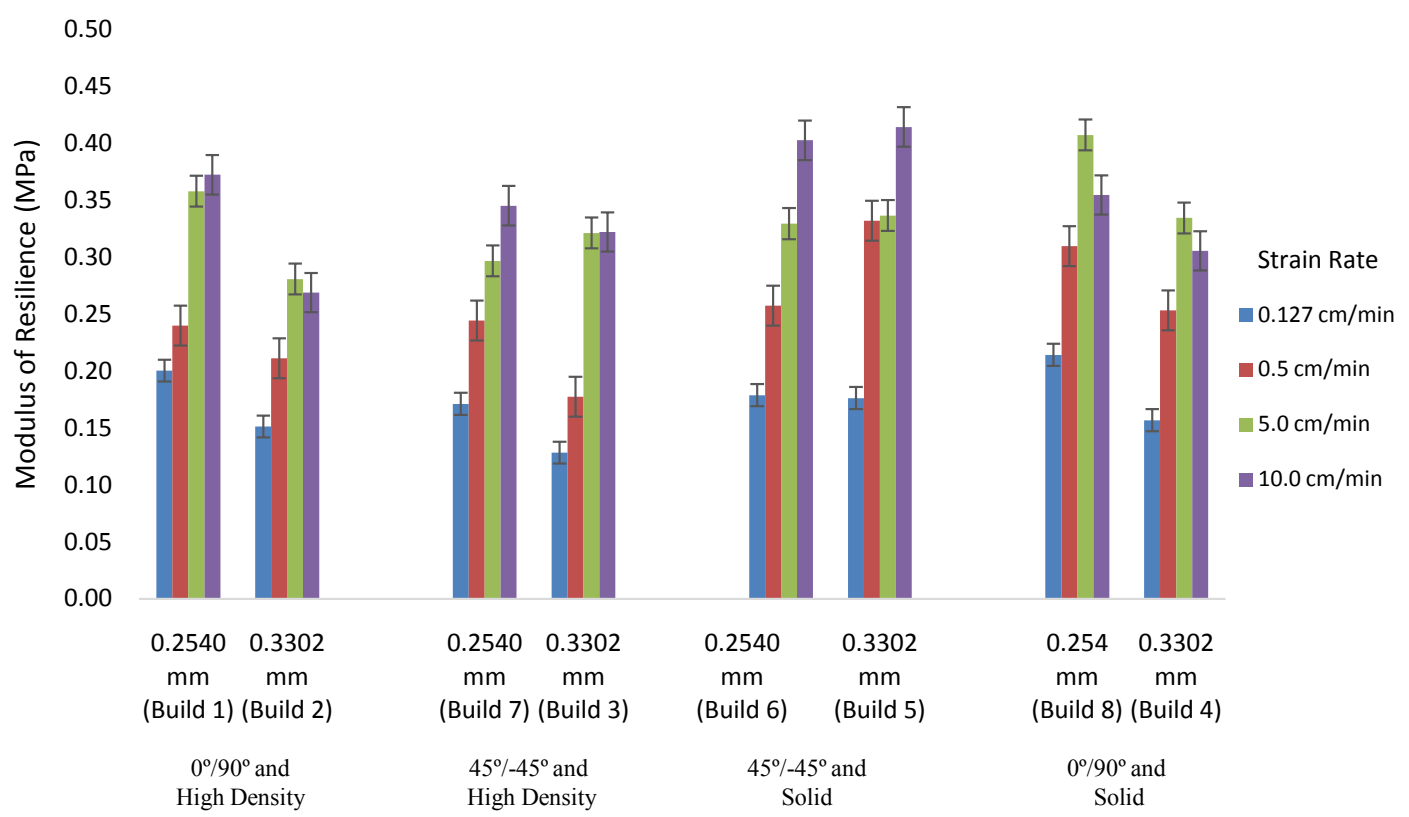

Figure 9. Effect of Layer Thickness on Modulus of Resilience.

shown in Figure 13 and Figure 14, respectively. These observations were deemed reasonable since the solid interior fill style can accommodate more stress due to its denser structure and higher effective cross-sectional area than that of the high density interior fill style. 
2.50

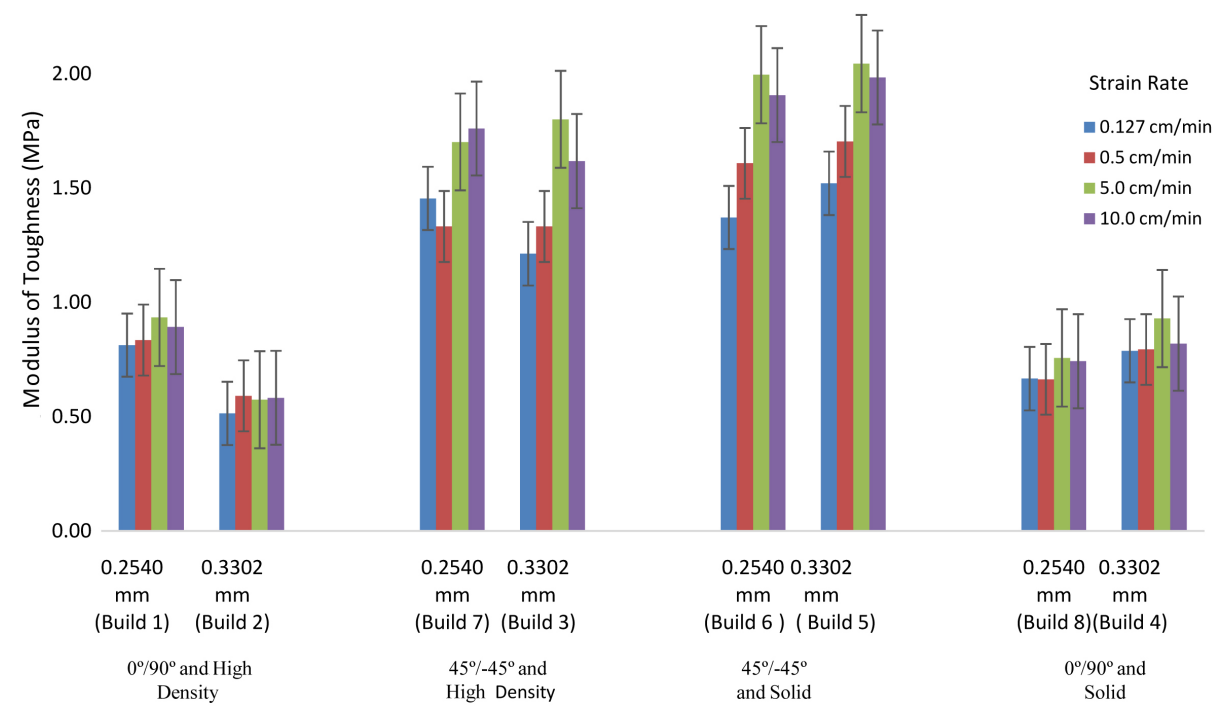

Figure 10. Effect of Layer Thickness on Modulus of Toughness.

30

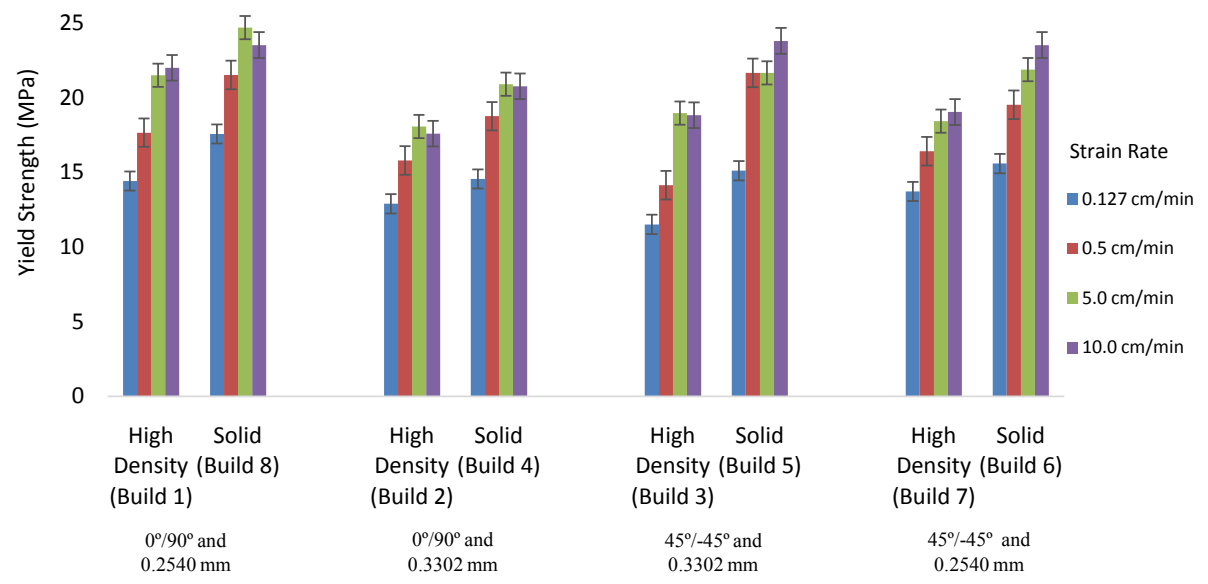

Figure 11. Effect of Interior Fill Style on Yield Strength.

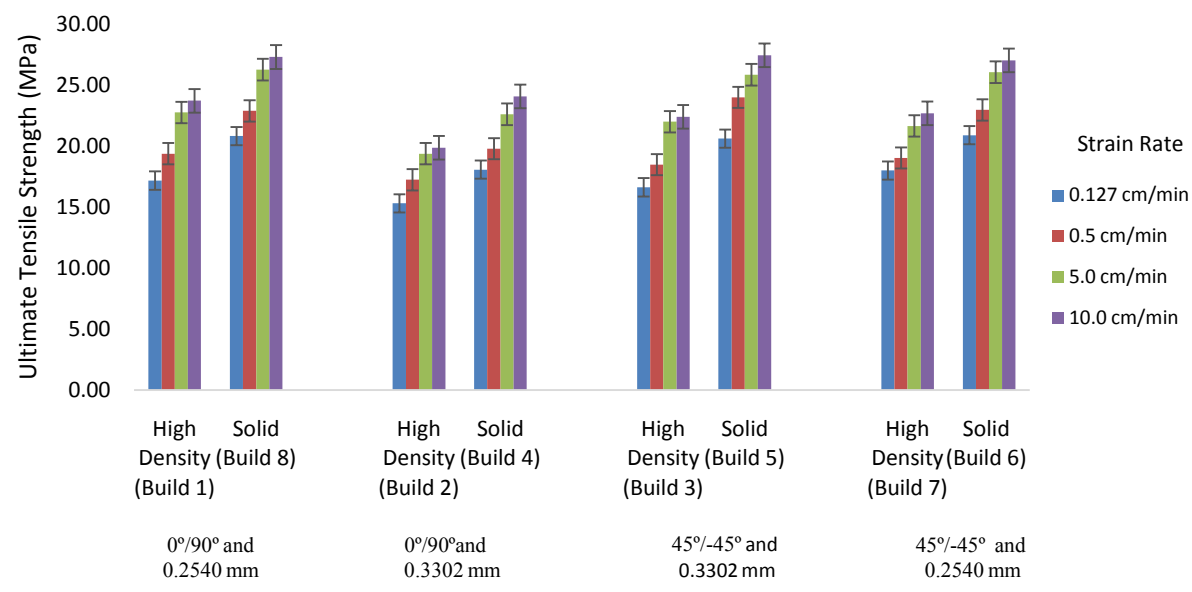

Figure 12. Effect of Interior Fill Style on Ultimate Tensile Strength. 


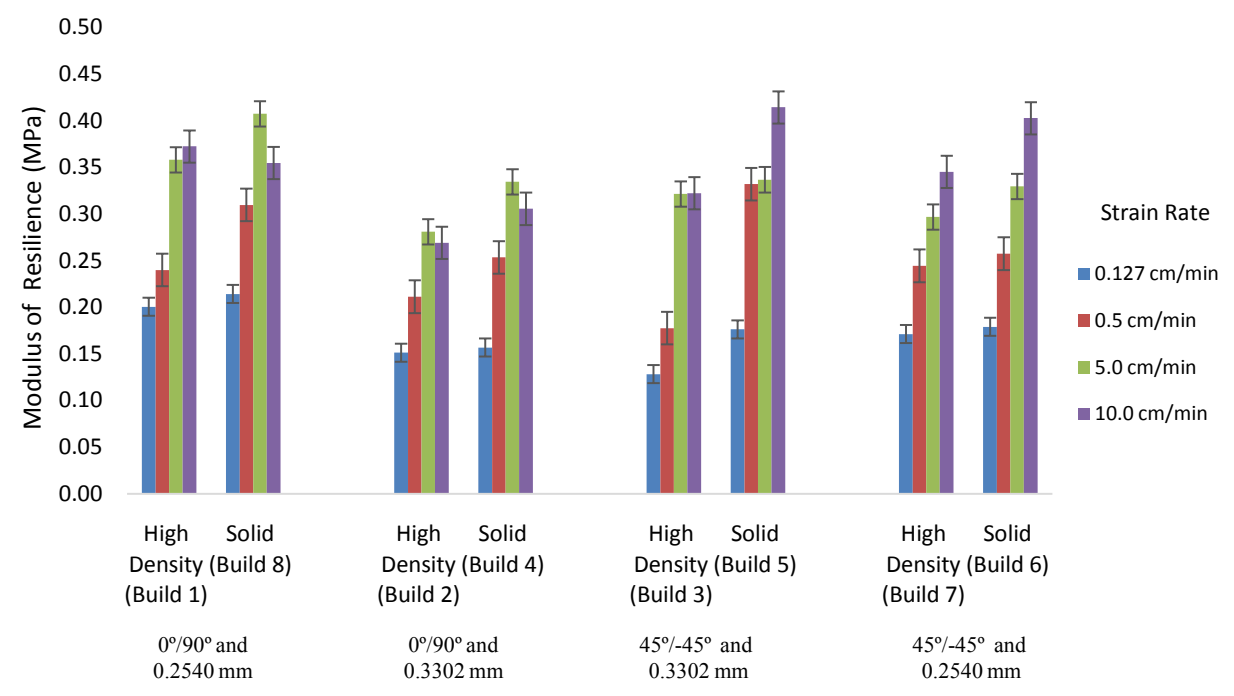

Figure 13. Effect of Interior Fill Style on Modulus of Resilience.

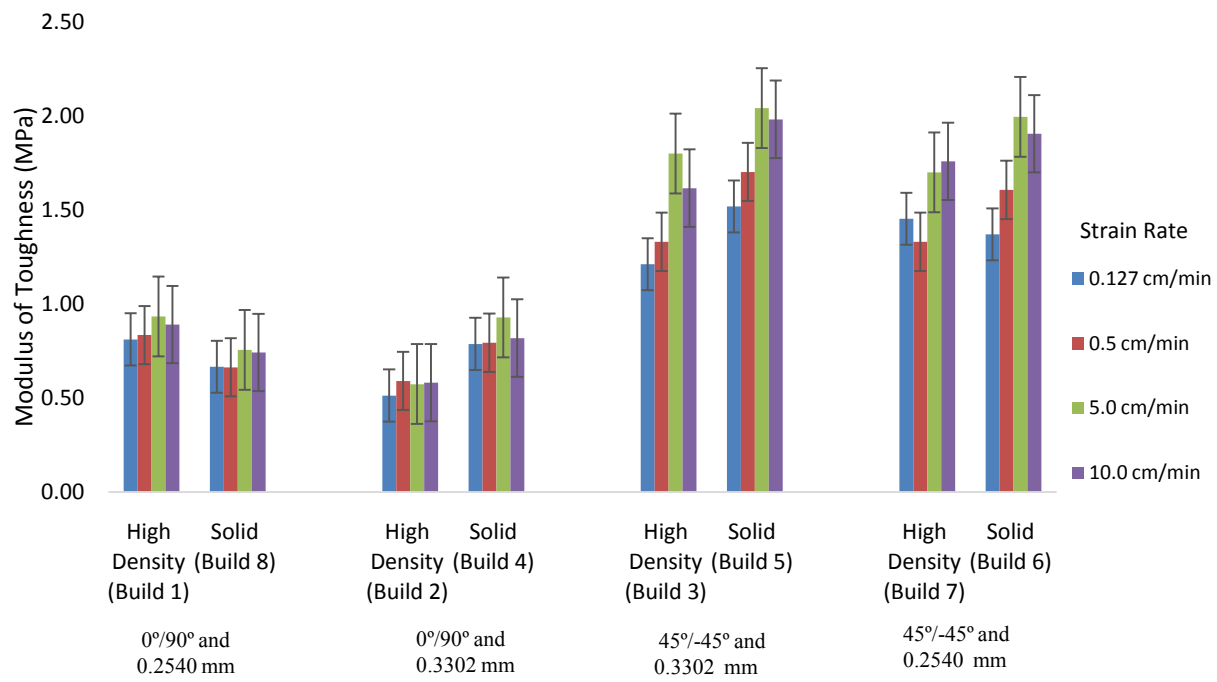

Figure 14. Effect of Interior Fill Style on Modulus of Toughness.

\subsection{Statistical Significance}

The summary of ANOVA for modulus of toughness, modulus of resilience, UTS and yield strength is illustrated in Tables 7-10. The modulus of toughness results indicated a dominant, statistically significant main effect of raster angle (A) (with a p-value $=0.000$ ) followed by a significant main effect in interior fill style $(C)(p$-value $=0.000)$ and strain rate $(D)(p$-value $=0.000)$. The main effect for layer thickness (B) was deemed insignificant. Analysis for the modulus of resilience implies a dominant, statistically significant main effect of strain rate $(\mathrm{D})$ ( $\mathrm{p}$-value $=0.000)$ followed by a significant main effect in interior fill style $(C)(p$-value $=0.000)$ and layer thickness $(B)(p$-value $=0.000)$. The main effect for raster angle (A) was considered insignificant with a p-value of 0.858 .

The ANOVA summary for UTS showed a dominant, statistically significant 
Table 7. ANOVA summary table for modulus of toughness.

\begin{tabular}{cccc}
\hline Source & P-Value & Effect Size & Significance \\
\hline A & 0.000 & 0.867 & Significant \\
B & 0.124 & 0.018 & Insignificant \\
C & 0.000 & 0.128 & Significant \\
D & 0.000 & 0.346 & Significant \\
\hline
\end{tabular}

Table 8. ANOVA summary table for modulus of resilience.

\begin{tabular}{cccc}
\hline Source & P-Value & Effect Size & Significance \\
\hline A & 0.858 & 0.000 & Insignificant \\
B & 0.000 & 0.221 & Significant \\
C & 0.000 & 0.329 & Significant \\
D & 0.000 & 0.846 & Significant \\
\hline
\end{tabular}

Table 9. ANOVA summary table for UTS.

\begin{tabular}{cccc}
\hline Source & P-Value & Effect Size & Significance \\
\hline A & 0.000 & 0.102 & Significant \\
B & 0.000 & 0.503 & Significant \\
C & 0.000 & 0.815 & Significant \\
D & 0.000 & 0.917 & Significant \\
\hline
\end{tabular}

Table 10. ANOVA summary table for yield strength.

\begin{tabular}{cccc}
\hline Source & P-Value & Effect Size & Significance \\
\hline A & 0.000 & 0.574 & Significant \\
B & 0.000 & 0.720 & Significant \\
C & 0.000 & 0.938 & Significant \\
D & 0.000 & 0.957 & Significant \\
\hline
\end{tabular}

main effect of strain rate $(D)$ (with a $\mathrm{p}$-value $=0.000$ ) and interior fill style $(C)$ (with a p-value $=0.000$ ). This is followed by significant main effects in layer thickness $(B)(p$-value $=0.000)$ and raster angle $(A)$ (p-value $=0.000)$. Also for yield strength, results showed a dominant, statistically significant main effect of strain rate $(D)(p$-value $=0.000)$ and interior fill style $(C)(p$-value $=0.000)$. This is followed by significant main effects in layer thickness $(B)$ ( $p$-value $=0.000$ ) and raster angle $(\mathrm{A})(\mathrm{p}$-value $=0.000)$.

\subsection{Stress-Strain Curves}

Figure 15 and Figure 16 illustrate the typical stress-strain behavior of specimens built with the cross $\left[0^{\circ} / 90^{\circ}\right]$ and crisscross $\left[45^{\circ} /-45^{\circ}\right]$ raster angles at a strain rate of $0.5 \mathrm{~cm} / \mathrm{min}$ in accordance with ASTM D638. The stress-strain curves for 


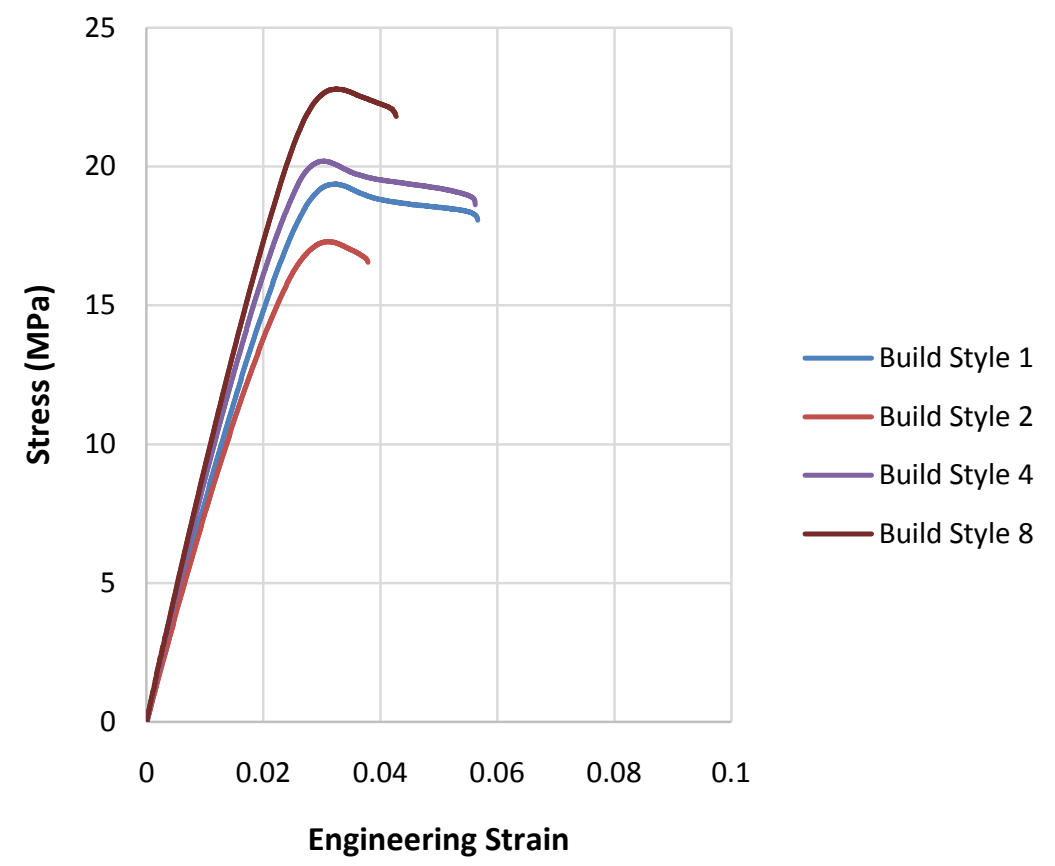

Figure 15. Stress Strain Curves for $\left[0^{\circ} / 90^{\circ}\right]$ Raster Angle Specimens at $0.5 \mathrm{~cm} / \mathrm{min}$.

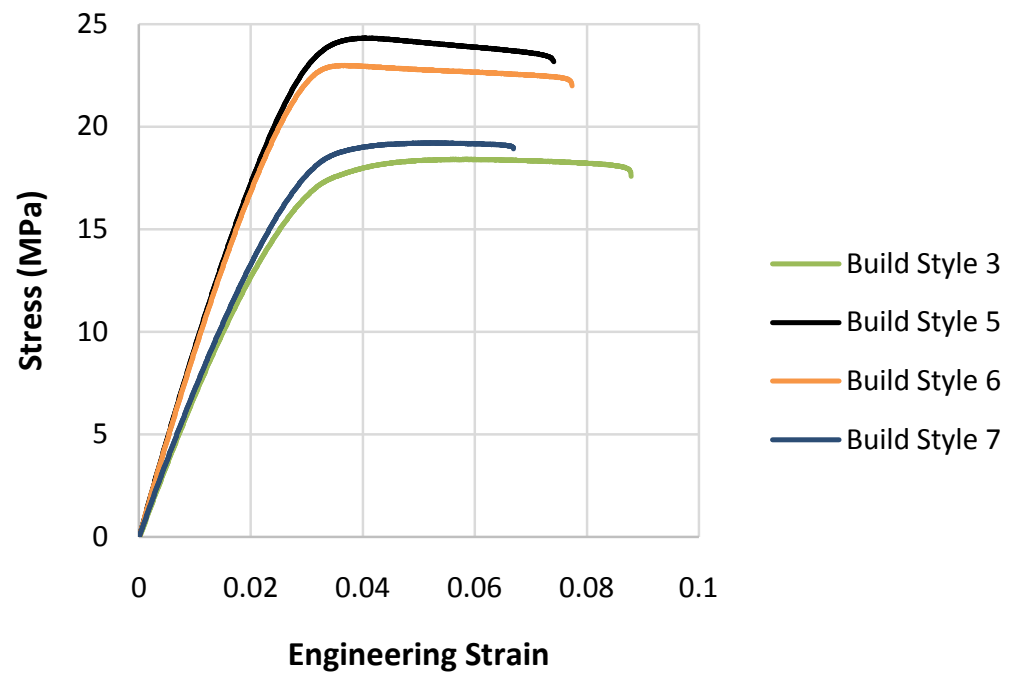

Figure 16. Stress Strain Curves for $\left[45^{\circ} /-45^{\circ}\right]$ Raster Angle Specimens at $0.5 \mathrm{~cm} / \mathrm{min}$.

build styles 1, 2, 4, and 8 (shown in Figure 15) represent those for a brittle material with the $\left[0^{\circ} / 90^{\circ}\right]$ raster angle being the only common process parameter among all the aforementioned build styles. Whereas, the stress-strain curves for build style 3, 5, 6, and 7 (shown in Figure 16) show a more ductile material as they undergo a much larger amount of plastic deformation prior to fracture. Build styles $3,5,6$, and 7 shared the $\left[45^{\circ} /-45^{\circ}\right]$ raster angle as the only common process parameter. Furthermore, build styles produced with the $\left[-45^{\circ} / 45^{\circ}\right]$ raster angle tends to favor the viscous/energy damping properties of ABS. This improves the modulus of toughness and ability to tolerate plastic deformation when compared to their $\left[0^{\circ} / 90^{\circ}\right]$ counterparts. 


\subsection{Strain Rate Sensitivity}

For all build styles, most mechanical properties investigated in this study exhibited modest sensitivity to the strain rate with the mean value of each property increasing as the strain rate is increased. From Figure 17 and Figure 19, a clear distinction between the UTS at the lower strain rates of $0.127 \mathrm{~cm} / \mathrm{min}$ and 0.5 $\mathrm{cm} / \mathrm{min}$ was observed. However, this difference is less pronounced at the higher strain rates of $5 \mathrm{~cm} / \mathrm{min}$ and $10 \mathrm{~cm} / \mathrm{min}$. For specimens produced with the $\left[0^{\circ} / 90^{\circ}\right]$ raster angle, the mode of failure tended to be more brittle in nature as the strain rate is increased. Surprisingly, this was not the case for specimens produced with the $\left[45^{\circ} /-45^{\circ}\right]$ raster angle as the strain rate seemed to have little effect on the mode of failure and its propensity for plastic deformation.

The effects of strain rate on the other mechanical properties are described using Figure 18-21 were generated with the mean values for each mechanical property over the four strain rates. Similar to the UTS, there is a distinctive increase

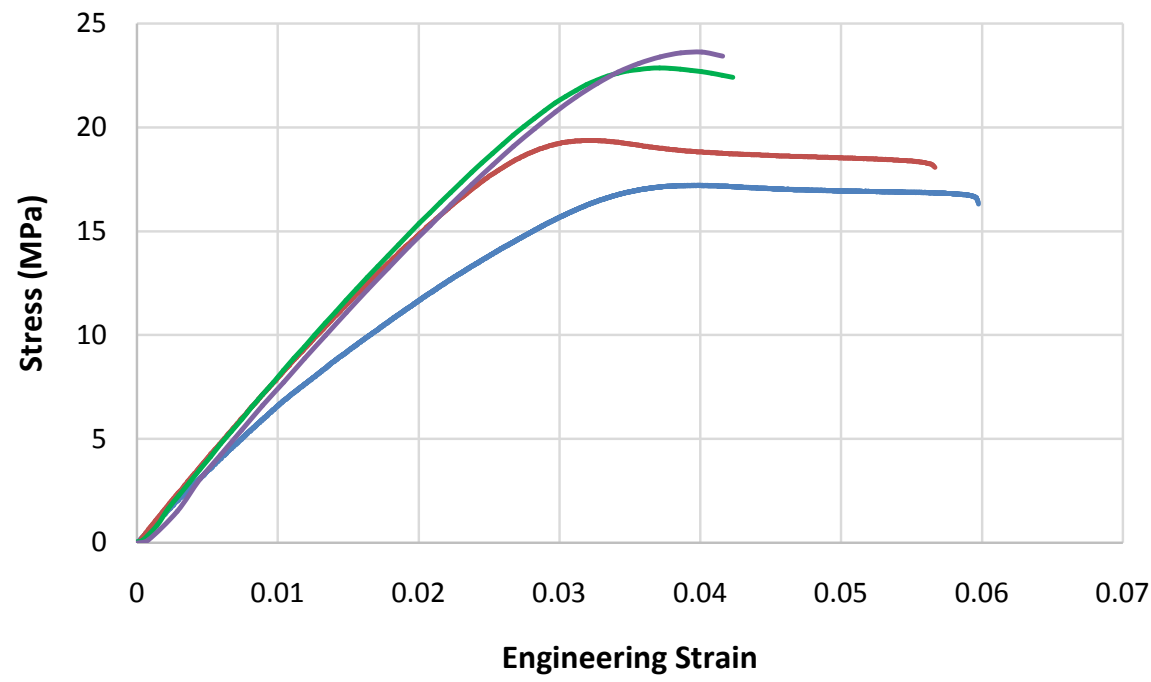

(a)

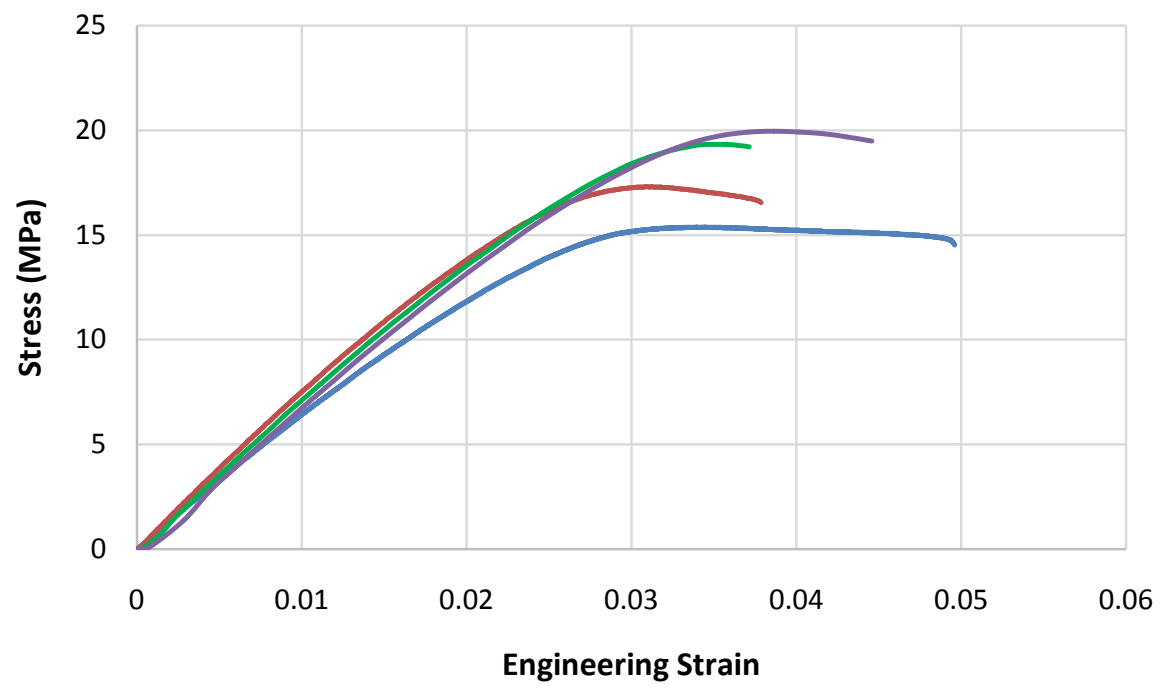

(b) 


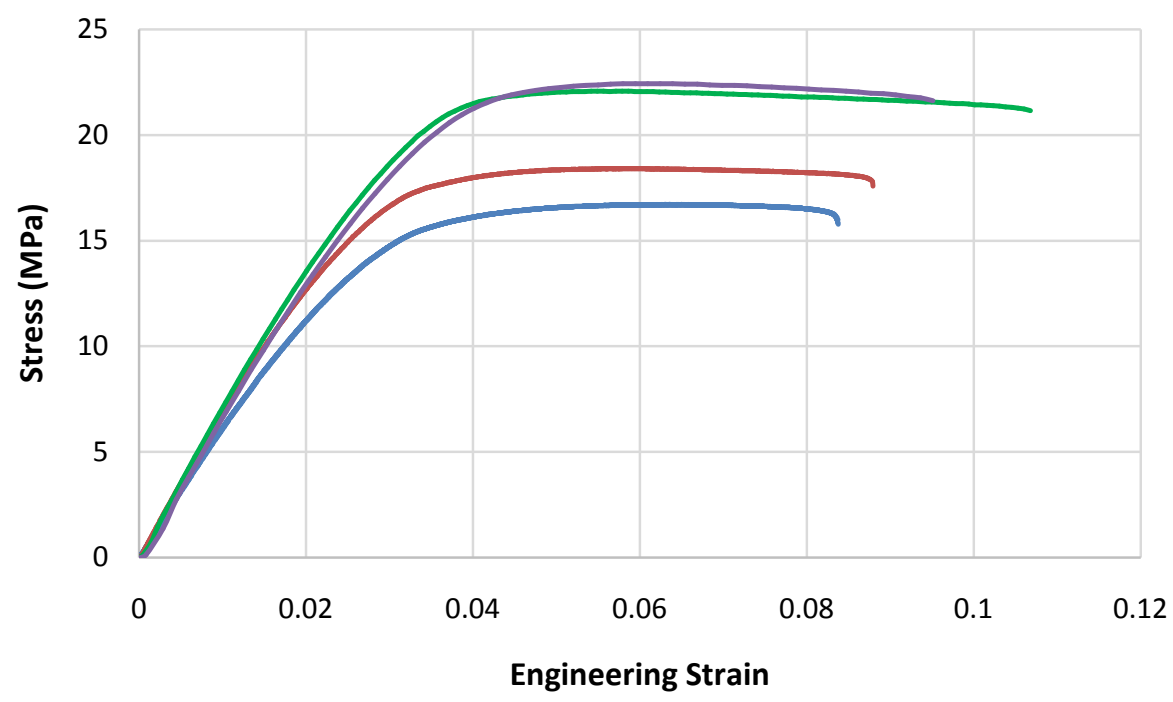

(c)

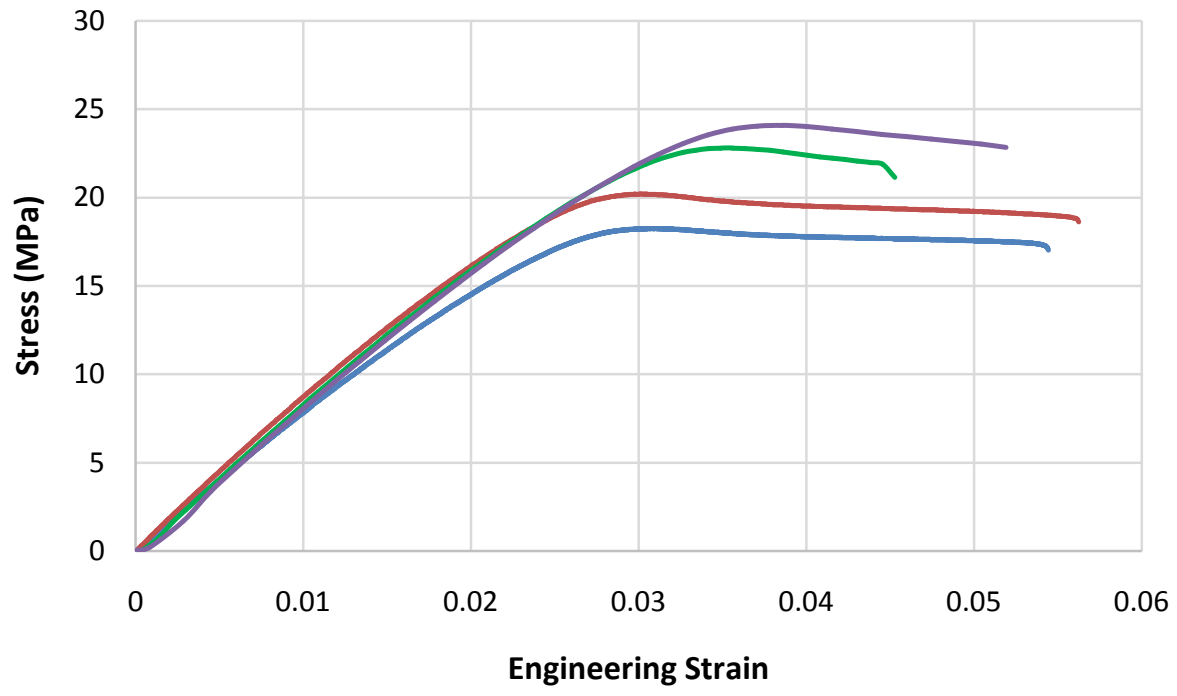

(d)

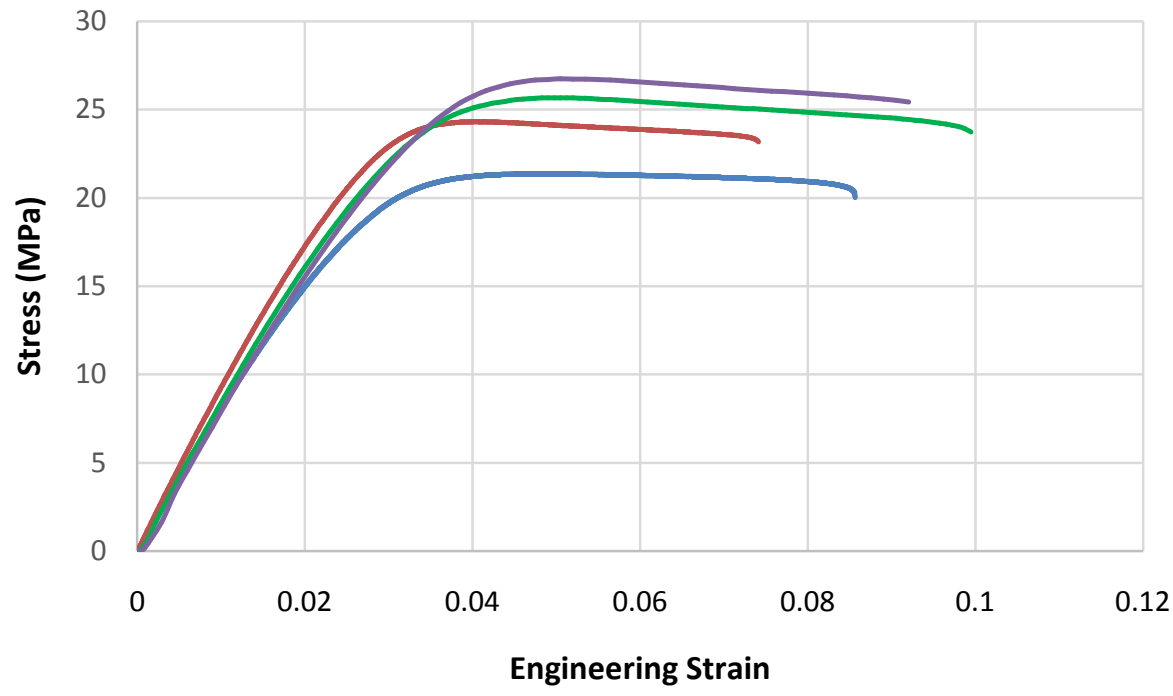

(e) 


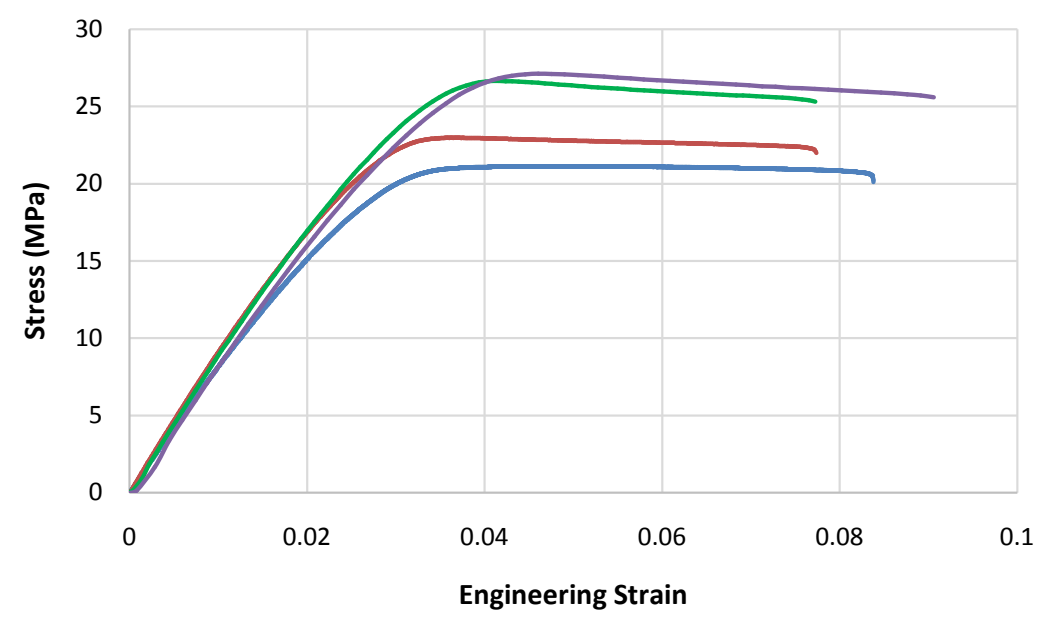

(f)

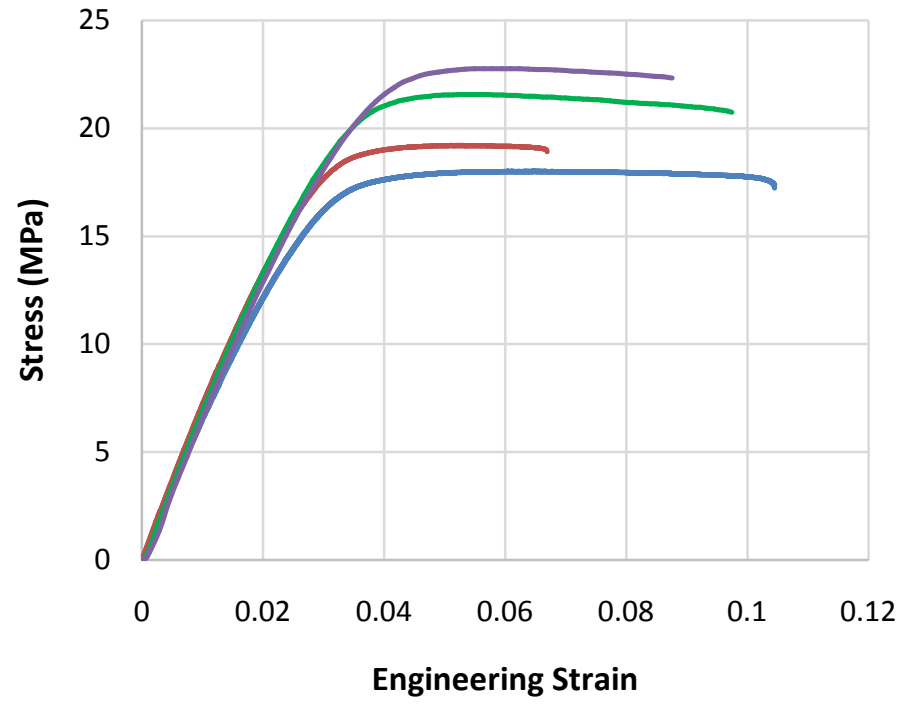

(g)

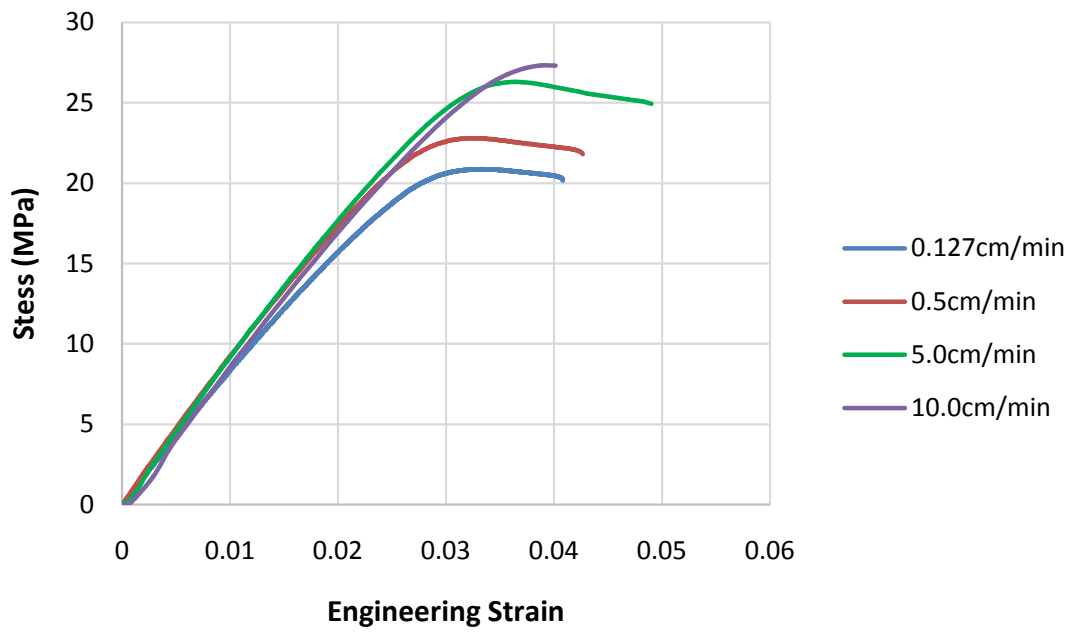

(h)

Figure 17. Strain rate sensitivity of 3D printed ABS with different build styles. (a) Build Style 1; (b) Build Style 2; (c) Build Style 3; (d) Build Style 4; (e) Build Style 5; (f) Build Style 6; (g) Build Style 7; (h) Build Style 8. 
30

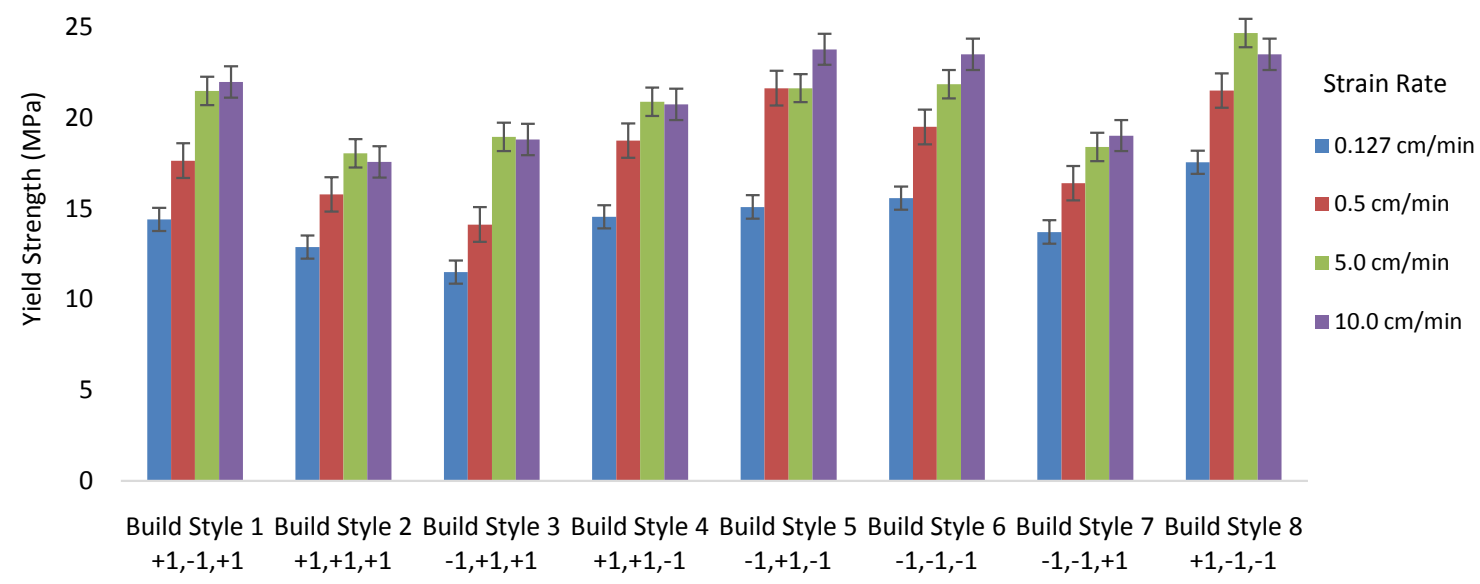

Figure 18. Effect of Strain Rate on Yield Strength.

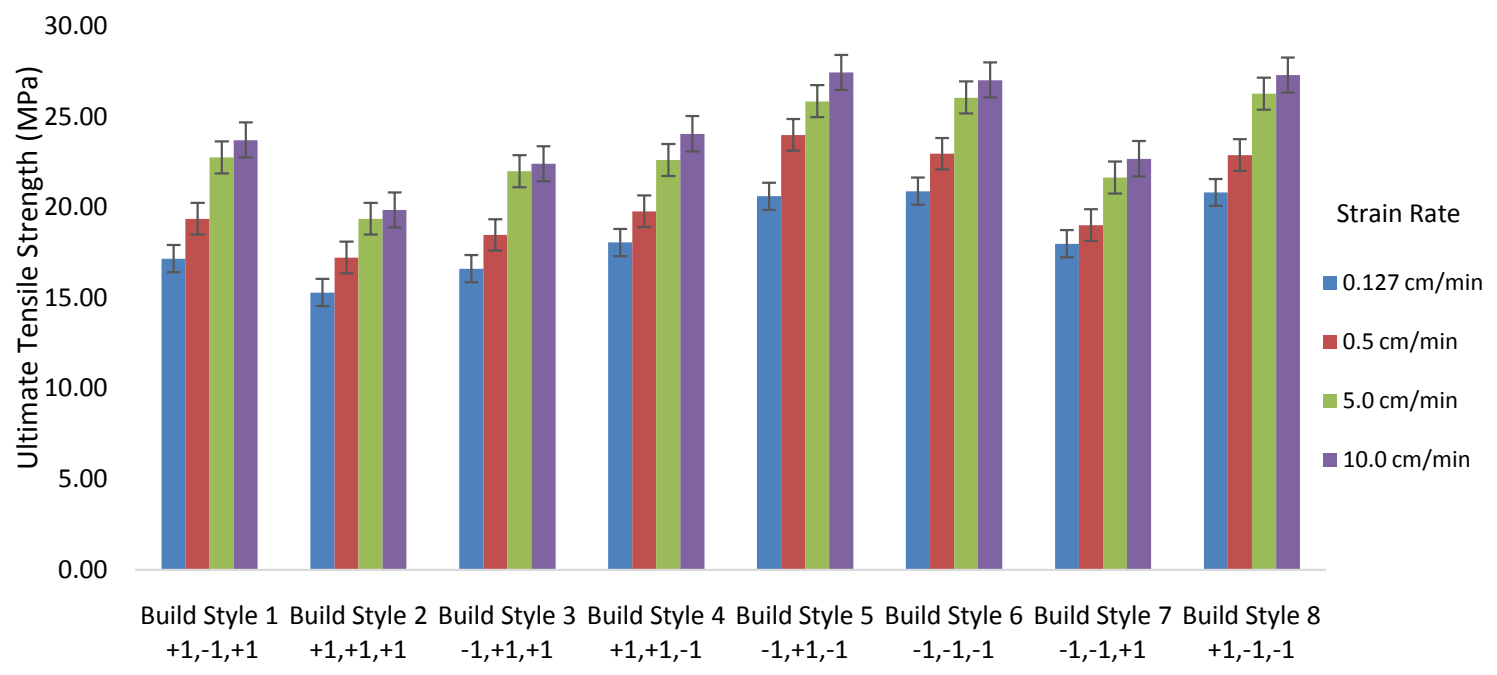

Figure 19. Effect of Strain Rate on Ultimate Tensile Strength.

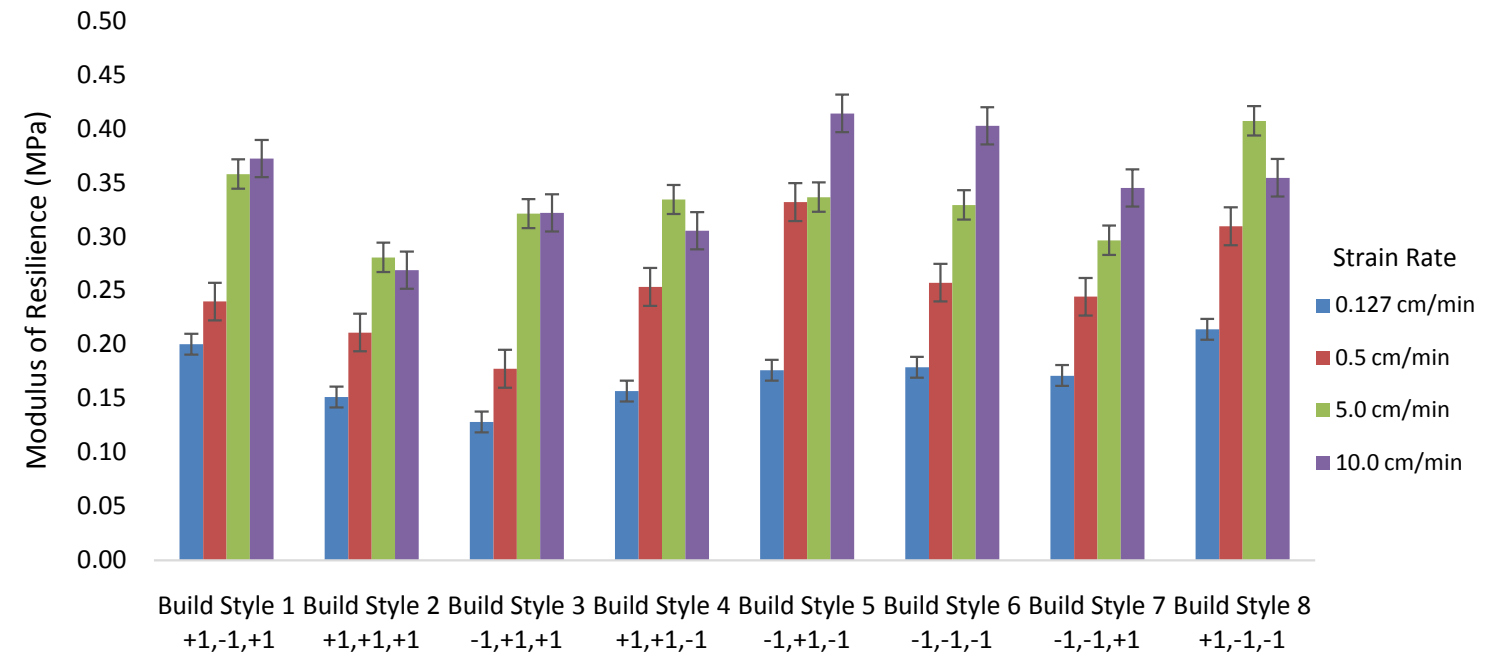

Figure 20. Effect of Strain Rate on Modulus of Resilience. 


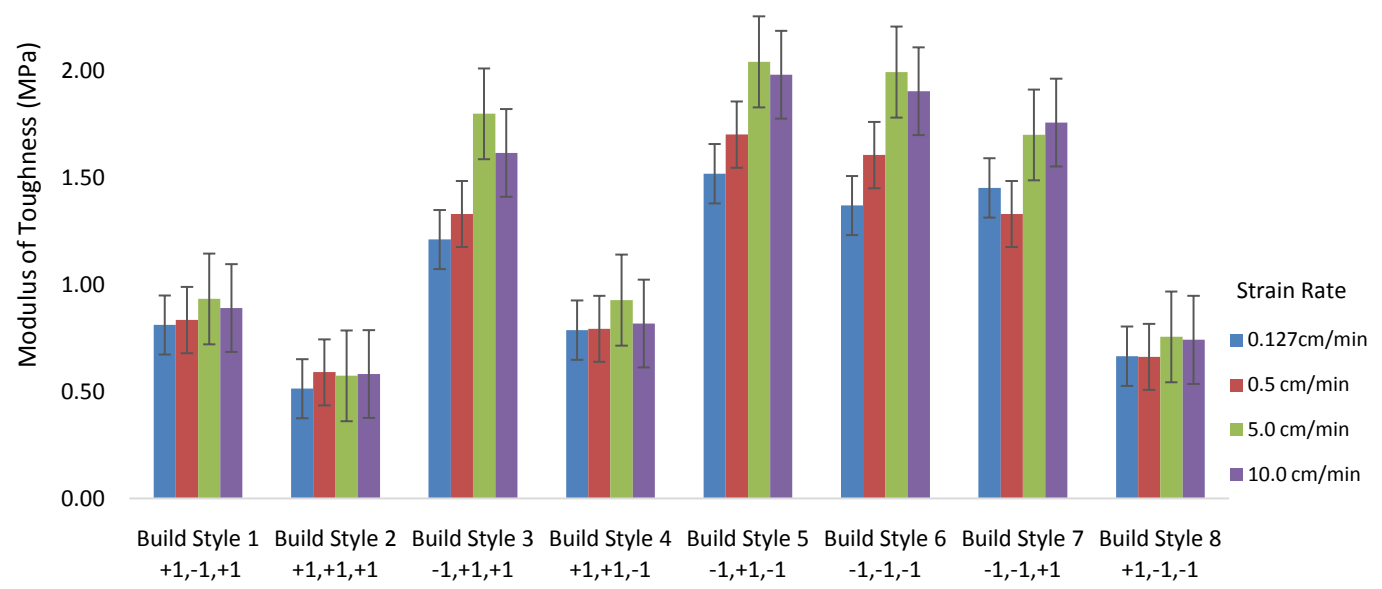

Figure 21. Effect of Strain Rate on Modulus of Toughness.

in the mean yield strength and modulus of resilience as the strain rate is increased from $0.127 \mathrm{~cm} / \mathrm{min}$ to $0.5 \mathrm{~cm} / \mathrm{min}$. However, there is significant overlap in the mean yield strength values at the higher strain rates of $5 \mathrm{~cm} / \mathrm{min}$ and 10 $\mathrm{cm} / \mathrm{min}$. Based on Figure 21, the effect of strain rate on the modulus of toughness seemed to depend on the build style. For specimens produced with the $\left[45^{\circ} /-45^{\circ}\right]$ raster angle, there was a noticeable increase in mean toughness as the strain rate increased. However, specimens produced with the $\left[0^{\circ} / 90^{\circ}\right]$ raster angle exhibit significant overlap in the mean toughness at all four strain rates.

\section{Conclusions}

This study focused on investigating the influence of build parameters on the mechanical properties of 3D-printed ABS manufactured using FDM. The following specific conclusions can be drawn based on this study:

1) The effect of raster angle was highly significant on modulus of toughness. Specimens built with the $\left[45^{\circ} /-45^{\circ}\right]$ raster angle have potentials for improving the modulus of toughness by $200 \%$ when compared to specimens built with the $\left[0^{\circ} / 90^{\circ}\right]$ raster angle. At a strain rate of $5 \mathrm{~cm} / \mathrm{min}$ and $\left[45^{\circ} /-45^{\circ}\right]$ raster angle, a substantial modulus of toughness $2.044 \mathrm{MPa}$ was achieved.

2) The modulus of resilience is strongly influenced by strain rate values. At any build style combinations of parameters, a significant improvement in modulus of resilience is achievable at higher strain rates. A very high modulus of resilience was achieved to be $0.414 \mathrm{MPa}$ with specimens built with the $\left[45^{\circ} /-45^{\circ}\right]$ raster angle and solid interior fill style.

3) The UTS and yield strength properties were observed to be dominantly affected by strain rate and interior fill style. High UTS of 27.44 MPa and yield strength of $23.79 \mathrm{MPa}$ were obtained with specimens built with the $\left[45^{\circ} /-45^{\circ}\right]$ raster angle and solid interior fill style at a strain rate of $10 \mathrm{~cm} / \mathrm{min}$.

4) Although specimens built with both $0.254 \mathrm{~mm}$ layer thickness and the cross $\left[0^{\circ} / 90^{\circ}\right]$ raster angle had superior mechanical properties to those built with the 
$0.3302 \mathrm{~mm}$ layer thickness and cross $\left[0^{\circ} / 90^{\circ}\right]$ raster angle, the effects of the layer thickness on the mechanical properties was found to be inconsistent. The implication of this is that the interaction between the layer thickness and the raster angle is significant.

5) Specimens built with the solid interior fill style have greater yield strength and UTS than those built with high density. This is mostly due to the added density in the solid fill style that allows the accommodation of more stress than the high density fill style.

Future study will focus on dynamic behavior and wear resistance of the 3Dprinted polymers to increase their potential applications in industry.

\section{Acknowledgements}

The authors gratefully acknowledge the financial support of Consortium for Advanced Manufacturing. The contributions of Wes Everhart (KCP) are also well appreciated.

\section{Data Availability Statement}

Data will be made available on request.

\section{Conflicts of Interest}

The authors declare no conflicts of interest regarding the publication of this paper.

\section{References}

[1] Yakovlev, A., Trunova, E., Grevey, D., Pilloz, M. and Smurov, I. (2005) Laser-Assisted Direct Manufacturing of Functionally Graded 3D Objects. Surface and Coatings Technology, 190, 15-24. https://doi.org/10.1016/j.surfcoat.2004.07.070

[2] Alimardani, M., Toyserkani, E. and Huissoon, J.P. (2007) Three-Dimensional Numerical Approach for Geometrical Prediction of Multilayer Laser Solid Freeform Fabrication Process. Journal of Laser Applications, 19, 14-25.

https://doi.org/10.2351/1.2402518

[3] Ivanova, O., Williams, C. and Thomas, C. (2013) Additive Manufacturing (AM) and Nanotechnology: Promises and Challenges. Rapid Prototyping Journal, 19, 353-364. https://doi.org/10.1108/RPJ-12-2011-0127

[4] Gurrala, P.K. and Regalla, S.P. (2014) DOE Based Parametric Study of Volumetric Change of FDM Parts. Procedia Materials Science, 6, 354-360.

https://doi.org/10.1016/j.mspro.2014.07.045

[5] Domingo-Espin, M., Puigoriol-Forcada, J.M., Garcia-Granada, A., Liuma, J., Borros, S. and Reyes, G. (2015) Mechanical Property Characterization and Simulation of Fused Deposition Modeling Polycarbonate Parts. Materials \& Design, 83, 670-677. https://doi.org/10.1016/j.matdes.2015.06.074

[6] Srivastava, M., Maheshwari, S. and Kundra, T.K. (2015) Virtual Modelling and Simulation of Functionally Graded Material Component using FDM Technique. Materials Today: Proceedings, 2, 3471-3480.

[7] Rao, R.V. and Rai, D.P. (2016) Optimization of Fused Deposition Modeling Process 
Using Teaching-Learning-Based Optimization Algorithms. Engineering Science and Technology, 19, 587-603. https://doi.org/10.1016/j.jestch.2015.09.008

[8] Wulle, F., Coupek, D., Schaffner, F., Verl, A., Oberhofer, F. and Maier, T. (2017) Workpiece and Machine Design in Additive Manufacturing for Multi-Axis Fused Deposition Modeling. Procedia CIRP, 60, 229-234. https://doi.org/10.1016/j.procir.2017.01.046

[9] Gross, B.C., Erkal, J.L., Lockwood, S.Y., Chen, C. and Spence, D.M. (2014) Evaluation of 3D Printing and Its Potential Impact on Biotechnology and the Chemical Sciences. Analytical Chemistry, 86, 3240-3253. https://doi.org/10.1021/ac403397r

[10] Slotwinski, J.A. and Moylan, S.P. (2014) Metals-Based Additives Manufacturing: Metrology Needs and Standardization Efforts. American Society for Precision Engineering, 57, 11-12.

[11] Wohler, T. (2012) Additive Manufacturing and 3D Printing State of the Industry. Wohlers' Report, Wohlers Associates Inc.

[12] Galantucci, L.M., Lavecchia, F. and Percoco, G. (2010) Quantitative Analysis of a Chemical Treatment to Reduce Roughness of Parts Fabricated Using Fused Deposition Modeling. CIRP Annals, 59, 247-250. https://doi.org/10.1016/j.cirp.2010.03.074

[13] I.D.C. (2016) Worldwide Spending on 3D Printing to Grow from Nearly \$11 Billion to $\$ 26.7$ Billion by 2019 . https://3dprint.com

[14] Forster, A.M. (2015) Materials Testing Standards for Additive Manufacturing of Polymer Materials: State of the Art and Standards Applicability. National Institute of Standard Technology. https://doi.org/10.6028/NIST.IR.8059

[15] Leon, A.C., Chen, Q., Palaganas, N.B., Palaganas, J.O., Manapat, J. and Advincala, R.C. (2016) High Performance Polymer Nanocomposites for Additive Manufacturing Applications. Reactive and Functional Polymers, 103, 141-155. https://doi.org/10.1016/j.reactfunctpolym.2016.04.010

[16] Gibson, I., Rosen, D.W. and Stucker, B. (2010) Additive Manufacturing Technologies-Rapid Prototyping to Direct Digital Manufacturing. Springer, Berlin, 459.

[17] Tekinalp, H.L., Kunc, V., Velez-Garcia, G.M., Duty, C.E., Love, L.J., Naskar, A.K., Blue, C.A. and Ozcan, S. (2014) Highly Oriented Carbon Fiber Polymer Composites via Additive Manufacturing. Composites Science and Technology, 105, 144-150. https://doi.org/10.1016/j.compscitech.2014.10.009

[18] Olsson, A., Hellsing, M.S. and Rennie, A.R. (2017) New Possibilities Using Additive Manufacturing with Materials That Are Difficult to Process and with Complex Structures, Royal Swedish Academy of Sciences. Physica Scripta, 92, 1-8. https://doi.org/10.1088/1402-4896/aa694e

[19] Kardel, K., Ghaednia, H., Carrano, A.L. and Marghitu, D.B. (2017) Experimental and Theoretical Modeling of Behavior of 3D-Printed Polymers under Collision with a Rigid Rod. Additive Manufacturing, 14, 87-94. https://doi.org/10.1016/j.addma.2017.01.004

[20] Wang, L. and Gardner, D.J. (2017) Effect of Fused Modeling Processing Parameters on Impact Strength of Cellular Polypropylene. Polymer, 113, 74-80. https://doi.org/10.1016/j.polymer.2017.02.055

[21] Ransikarbum, K., Ha, S., Ma, J. and Kim, N. (2017) Multi-Objective Optimization Analysis for Part-to-Printer Assignment in a Network of 3D Fused Deposition Modeling. Journal of Manufacturing Systems, 43, 35-46. https://doi.org/10.1016/j.jmsy.2017.02.012

[22] Sood, A.K., Ohdar, R.K. and Mahapatra, S.S. (2012) Experimental Investigation and 
Empirical Modelling of FDM Process for Compressive Strength Improvement. Journal of Advanced Research, 3, 81-90. https://doi.org/10.1016/j.jare.2011.05.001

[23] Lee, B.H., Abdullah, J. and Khan, Z.A. (2005) Optimization of Rapid Prototyping Parameters for Production of Flexible ABS Object. Journal of Materials Processing Technology, 169, 54-61. https://doi.org/10.1016/j.jmatprotec.2005.02.259

[24] Raut, S., Jaitti, V.S., Khedhar, N.K. and Singh, T.P. (2014) Investigation of the Effect of Built Orientation on Mechanical Properties and Total Cost of FDM Parts. Procedia Materials Science, 6, 1625-1630. https://doi.org/10.1016/j.mspro.2014.07.146

[25] Ning, F., Cong, W., Qiu, J., Wei, J. and Wang, S. (2015) Additive Manufacturing of Carbon Reinforced Thermoplastic Composites using Fused Deposition Modeling. Composites Part B: Engineering, 80, 369-378.

https://doi.org/10.1016/j.compositesb.2015.06.013

[26] Lederle, F., Gabriella, F.M., Brunotte, P., Kaldun, C. and Hubner, E.G. (2016) Improved Mechanical Properties of 3D-Printed Parts by Fused Deposition Modeling Processed under the Exclusion of Oxygen. Progress in Additive Manufacturing, 1, 3-7. https://doi.org/10.1007/s40964-016-0010-y

[27] Dul, S., Fambri, L. and Pegoretti, A. (2016) Fused Deposition Modeling with ABS Graphene Nanocomposites. Composites Part A: Applied Science and Manufacturing, 85, 181-191. https://doi.org/10.1016/j.compositesa.2016.03.013

[28] Alhijjaj, M., Belton, P. and Qi, S. (2016) An Investigation to the Use of Polymer Blends to Improve the Printability of and Regulate Drug Release from Pharmaceutical Solid Dispersions Prepared via Fused Deposition Modeling (FDM) 3D Printing. European Journal of Pharmaceutics and Biopharmaceutics, 108, 111-125. https://doi.org/10.1016/j.ejpb.2016.08.016

[29] Shemelya, C., Rosa, A.D.L., Torrado, A.R., Yu, K., Domanowski, J., Bonacuse, P.J., Martin, R.E., Juhasz, M., Hurwiftz, F., Wicker, R.B., Conner, B., MacDonald, E. and Roberson, D.A. (2017) Anisotropy of Thermal Conductivity in 3D Printed Polymer Matrix Composites for Space Based Cube Satellites. Additive Manufacturing, 16, 186-196. https://doi.org/10.1016/j.addma.2017.05.012

[30] Huang, B. and Singamneni, S. (2014) Raster Angle Mechanics in Fused Deposition Modelling. Journal of Composite Materials, 49, 363-383. https://doi.org/10.1177/0021998313519153

[31] Alaimo, G., Marconi, S., Costato, L. and Auricchi, F. (2017) Influence of Meso-Structure and Chemical Composition on FDM 3-D Printed Parts. Composites Part B: Engineering, 113, 371-380. https://doi.org/10.1016/j.compositesb.2017.01.019

[32] Owolabi, G., Peterson, A., Habtour, E., Riddict, J., Coalney, M., Olasumboye, A. and Boiling, D. (2016) Dynamic Response of Acrylonitrile Butadiene Styrene under Impact Loading. International Journal of Mechanical and Materials Engineering, 11, 1-8. https://doi.org/10.1186/s40712-016-0056-0

[33] Du, J., Wei, Z., Wang, X., Wang, J. and Chen, Z. (2016) An Improved Fused Deposition Modeling Process for Forming Large Size Thin Walled Parts. Journal of Materials Processing Technology, 234, 332-341. https://doi.org/10.1016/j.jmatprotec.2016.04.005

[34] Alafaghani, A., Qattawi, A., Alrawi, B. and Guzman, A. (2017) Experimental Optimization of Fused Deposition Modelling Processing Parameters: Design for Manufacturing Approach. Procedia Manufacturing, 10, 791-803. https://doi.org/10.1016/j.promfg.2017.07.079

[35] Guessama, S., Belhabib, S., Nouri, H. and Hassana, O.B. (2016) Anisotropic Damage 
Inferred to 3D-Printed Polymers Using Fused Deposition Modelling and Subject to Severe Compressions. European Polymer Journal, 85, 324-340.

https://doi.org/10.1016/j.eurpolymj.2016.10.030

[36] Griffiths, C.A., Howarth, J., Rowbotham, G.D. and Rees, A. (2016) Effect of Build Parameters on Processing Efficiency and Material Performance in Fused Deposition Modelling. Procedia CIRP, 49, 28-32. https://doi.org/10.1016/j.procir.2015.07.024

[37] Srivastava, M., Macheshwari, S., Kundra, T.K. and Rathee, S. (2017) Multi-Response Optimization of Fused Deposition Modelling Process Parameters of ABS Using Response Surface Methodology (RSM)-Based Desirability. Materials Today. Proceedings, 4, 1972-1977. https://doi.org/10.1016/j.matpr.2017.02.043

[38] Anitha, R., Arunachalam, S. and Radhakrishman, P. (2001) Critical Parameters Influencing the Quality of Prototypes in Fused Deposition Modelling. Journal of Materials Processing Technology, 118, 385-388. https://doi.org/10.1016/S0924-0136(01)00980-3

[39] Novakova-Marcincinova, L. and Novak-Marcincin, J. (2012) Testing of Materials for Prototyping Fused Deposition Modelling Technology. International Journal of Industrial and Manufacturing Engineering, 6, 2082-2085.

[40] Arsat, A.N.B. (2015) Study on the Properties of Parts Manufacture Using Fused Deposition Modelling (FDM). Bachelor of Mechanical Engineering Thesis, Faculty of Mechanical Engineering, Universiti Technikal, Malaysia Melaka, 1-24.

[41] Wu, W., Geng, P., Li, G., Zhao, D., Zhang, H. and Zhao, J. (2015) Influence of Layer Thickness and Raster Angle on the Mechanical Properties of 3D-Printed and PEEK and a Comparative Mechanical Study between PEEK and ABS Materials. Materials, 8, 5834-5846. https://doi.org/10.3390/ma8095271

[42] Luzamin, O., Mourin, D. and Plancak, M. (2014) Effect of Layer Thickness, Deposition Angle and Infill on Maximum Flexural Force in FDM-Built Specimens. Journal for Technology of Plasticity, 39, 50-59.

[43] Gardan, J., Makke, A. and Recho, N. (2016) A Method to Improve the Fracture Toughness Using 3D Printing Extrusion Deposition. Procedia Structural Integrity, 2, 144-151. https://doi.org/10.1016/j.prostr.2016.06.019

[44] Fischer, M. and Schoppner, V. (2017) Fatigue Behaviour of FDM Parts Manufactured with Ultem 9085. Journal of the Minerals, Metals, and Materials Society, 69, 563-568. https://doi.org/10.1007/s11837-016-2197-2

[45] Kay, R.N. (2014) Effect of Raster Orientation on the Structural Properties of Components Fabricated by Fused Deposition Modelling. Master of Science, Thesis in Mechanical Engineering, Ohio State University, Columbus, 1-145.

[46] Roberson, R.A., Angel, R., Perez, T., Shemelya, C.M., Rivera, A., MacDonald, E. and Wicker, R.B. (2015) Comparison of Stress Concentrator Fabrication for 3D Printed Polymeric Izod Impact Test Specimens. Additive Manufacturing, 7, 1-11. https://doi.org/10.1016/j.addma.2015.05.002

[47] Patel, R., Shah, H.N. and Kumari, S.V. (2015) Experimental Investigation of Fracture of ABS Material by ASTM-5045 for Different Crack Length and Layer of Orientation Using FDM Process. International Journal of Mechanical and Industrial Technology, 3, 77-83.

[48] Riddick, J.C., Haile, M., Wahlde, R.V., Cole, D.P., Bamiduro, O. and Johnson, T.E. (2016) Fractographic Analysis of Tensile Failure of Acryonitrile Butadiene Styrene Fabricated by Fused Deposition Modeling. Additive Manufacturing, 11, 49-59. https://doi.org/10.1016/j.addma.2016.03.007

[49] Zou, R., Xia, Y., Liu, S., Hu, P., Hou, W., Hu, Q. and Shan, C. (2016) Isotropic and 
Anisotropic Elasticity and Yielding of 3D Printed Material. Composites Part B: Engineering, 99, 506-513. https://doi.org/10.1016/j.compositesb.2016.06.009

[50] Rankouhi, B., Javadpour, S. and Delfanian, F. (2016) Failure Analysis and Mechanical Characterization of 3D Printed ABS with Respect to Layer Thickness and Orientation. Journal of Failure Analysis and Prevention, 16, 467-481. https://doi.org/10.1007/s11668-016-0113-2

[51] Mishra, S.B. (2016) A Study on Parametric Appraisal of Fused Deposition Modelling. PhD Thesis, National Institute of Technology, Rourkela, 1-126.

[52] Dawoud, M., Taha, I. and Ebeid, S.J. (2016) Mechanical Behavior of ABS: An Experimental Study using FDM and Injection Moulding Techniques. Journal of Manufacturing Processes, 21, 39-45. https://doi.org/10.1016/j.jmapro.2015.11.002

[53] Turk, D., Brenni, F., Zogg, M. and Meboldt, M. (2017) Mechanical Characterization of 3D Printed Polymers Processing. Materials \& Design, 118, 256-265. https://doi.org/10.1016/j.matdes.2017.01.050

[54] Aliheidari, N., Tripuraneni, R., Ameli, A. and Nadimpalli, S. (2017) Fracture Resistance Measurement of Fused Deposition Modeling 3D Printed Polymer. Polymer Testing, 60, 94-101. https://doi.org/10.1016/j.polymertesting.2017.03.016

[55] Faes, M., Ferrans, E. and Moens, D. (2016) Influence of Interlayer Cooling Time on the Quasi-Static Properties of ABS Components Produced via Fused Deposition Modelling. Procedia CIRP, 42, 748-753. https://doi.org/10.1016/j.procir.2016.02.313

[56] A.S.T.MD638-10 (2014) Standard Test Method for Tensile Properties of Plastics. ASTM International, West Conshohocken. http://www.astm.org 